
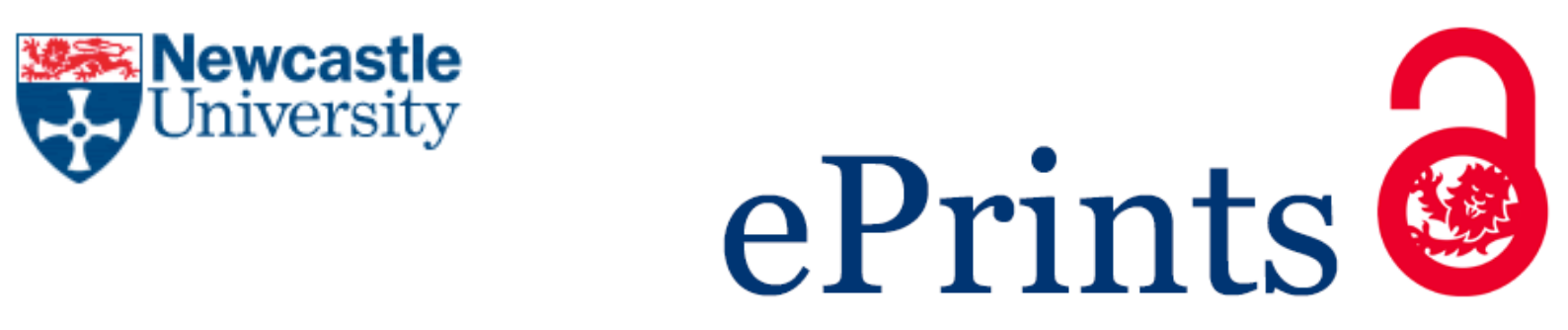

Kolawole OM, Lau WM, Mostafid H, Khutoryanskiy VV.

Advances in intravesical drug delivery systems to treat bladder cancer. International Journal of Pharmaceutics 2017, 532(1), 105-117.

\title{
Copyright:
}

(C) 2017. This manuscript version is made available under the CC-BY-NC-ND 4.0 license

DOI link to article:

https://doi.org/10.1016/j.ijpharm.2017.08.120

Date deposited:

$05 / 03 / 2018$

Embargo release date:

01 September 2018

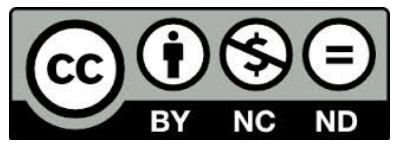

This work is licensed under a

Creative Commons Attribution-NonCommercial-NoDerivatives 4.0 International licence 


\section{Advances in intravesical drug delivery systems to treat bladder cancer}

Oluwadamilola M. Kolawole ${ }^{a}$, Wing-Man Lau ${ }^{a}$, Hugh Mostafid ${ }^{b}$, Vitaliy V. Khutoryanskiy ${ }^{a^{*}}$

aReading School of Pharmacy, University of Reading, Whiteknights, PO box 224, RG6 6AD

Reading, Berkshire, United Kingdom

${ }^{b}$ Department of Urology, Royal Surrey County Hospital, Guildford, Berkshire, United Kingdom

*Corresponding author at: Department of Pharmacy, University of Reading, Whiteknights, Reading, United Kingdom, RG6 6AD. Tel.: +44 (0) 118378 6119. E-mail address:

v.khutoryanskiy@reading.ac.uk

\section{ABSTRACT:}

Chemotherapeutic agents administered intravesically to treat bladder cancer have limited efficacy due to periodic dilution and wash-out during urine formation and elimination. This review describes the pathophysiology, prevalence and staging of bladder cancer, and discusses several formulation strategies used to improve drug residence within the bladder. These include the use of amphiphilic copolymers, mucoadhesive formulations, hydrogels, floating systems, and liposomes. Various in vitro and in vivo models recently employed for intravesical drug delivery studies are discussed. Some of the challenges that have prevented the clinical use of some promising formulations are identified.

Keywords: Bladder Cancer; Intravesical drug delivery; Particulate delivery systems; In situ gelling systems; Mucoadhesive; Floating 


\section{Introduction}

Bladder cancer $(\mathrm{BC})$ is the most predominant malignancy affecting the urinary tract, characterised by proliferation of abnormal cells in the urothelial lining of the urinary bladder. It is commonly divided into non-muscle invasive bladder cancer (NMIBC) which makes up $80 \%$ of cases at presentation and muscle invasive bladder cancer (MIBC) where the cancer extends into the underlying smooth muscle. The latter makes up $15 \%$ of cases at presentation with the remaining $5 \%$ presenting with metastases (Cheung et al., 2013). Intravesical therapy is only effective in NMIBC and is never used in MIBC. Haematuria is the commonest symptom in $85 \%$ patients but other clinical presentations may include urinary urgency and painful urination (Kaufman et al., 2009). It is ranked $7^{\text {th }}$ and $9^{\text {th }}$ in terms of cancer incidence in the United Kingdom (UK) and worldwide, respectively (Cheung et al., 2013; Torre et al., 2015) as well as being the fifth based on prevalent cancer types among European men (Aziz et al., 2016).

In 2015 in the UK, 6,169 new BC cases were diagnosed in men versus 2,331 new cases in women (Cancer Research, 2017) and it is projected that by 2035 there will be 7,771 BC related deaths per year (Cancer Research UK, 2016). BC is statistically twice as prevalent in the white population than in the black population; however in terms of mortality (Schinkel et al., 2016), with five-year survival rate is considerably higher in the white community $(80 \%)$ in comparison with the black community (64\%) (Torre et al., 2015). The greatest risk factor for BC is smoking and the risk is 2 to 6 fold higher for smokers than non-smokers, and is responsible for almost $31 \%$ and $14 \%$ of BC deaths in male and female smokers, respectively (Torre et al., 2015). In Africa, 50\% of BC patients have a previous history of infection with the water-borne parasite, Schistosoma hematobium, whereas the incidence of such BC cases worldwide is only $3 \%$ (Sievert et al., 2009).

Non-muscle invasive bladder cancer (NMIBC), also called superficial BC is the most prevalent form of $B C$ at first diagnosis. It progresses to MIBC in about $15 \%$ of patients with a poor prognosis despite transurethral resection of the bladder tumor (TURBT) and Bacillus Calmette-Guérin (BCG) immunotherapy (Williams et al., 2010) and therefore frequent cystoscopic surveillance of the bladder is necessary following initial therapy (Torre et al., 2015). BC has the highest cost of therapy of any cancer over the lifetime of the affected individual due to the associated cost of surveillance and treatment (D. A. Barocas et al., 2012; Sievert et al., 2009; Yeung et al., 2014).Therefore, improved $\mathrm{BC}$ therapeutic delivery systems have been investigated over the last two decades (Figure 1) in an attempt to reduce the clinical and economic burden of this disease. 


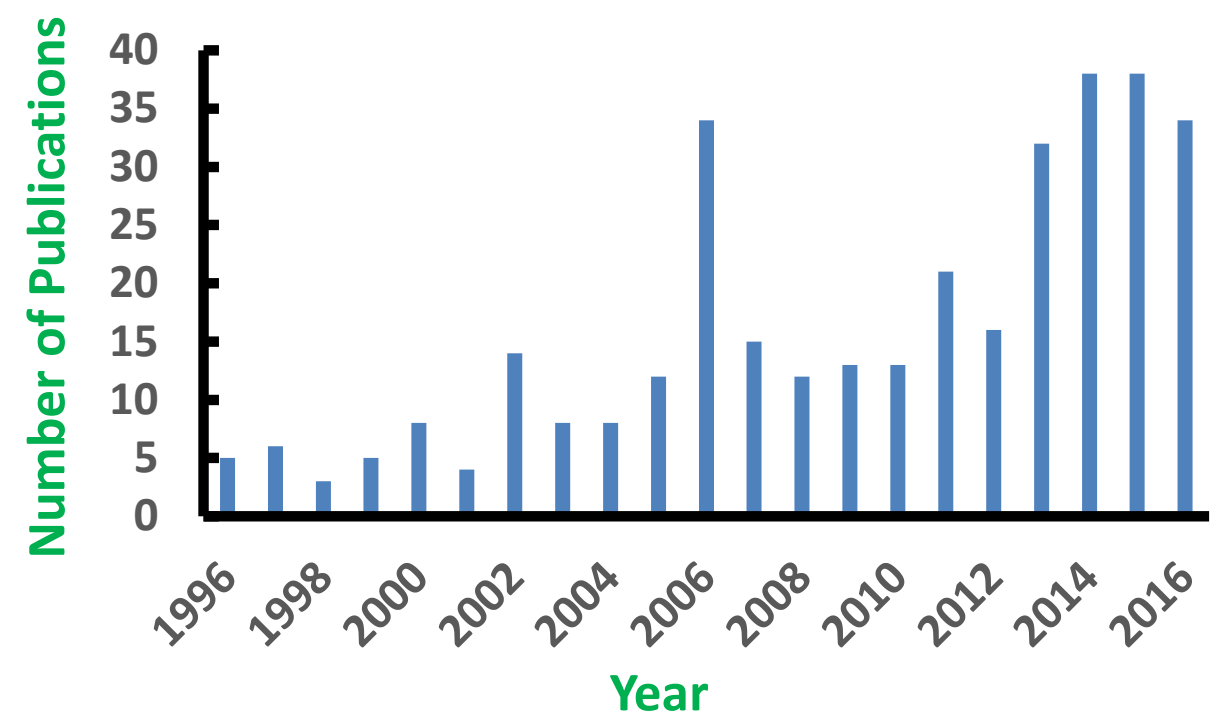

Figure 1: Number of publications reporting bladder cancer therapeutic delivery systems (19962016), Source: Web of Knowledge (search terms: bladder cancer, delivery systems).

The degradative hepatic enzymes and gastric acid lowers oral bioavailability of BC therapeutic formulations while systemic therapy is less efficient due to the poorly vascularised urothelium (Elstad and Fowers, 2009; GuhaSarkar and Banerjee, 2010). Increasing systemic drug dose with the aim of improving local drug concentration within the bladder leads to elevated adverse drug reactions and non-selective toxic effects on healthy tissues (GuhaSarkar and Banerjee, 2010). Intravesical Drug Delivery (IDD) (Figure 2) is the instillation of one or multiple therapeutic agents through a catheter, directly into the bladder (Zhang et al., 2014). IDD provides site-specific drug delivery with minimal toxicity (GuhaSarkar and Banerjee, 2010); and this may help to reduce tumor recurrence and progression (van Rhijn et al., 2009) because localised therapy improves therapeutic drug concentrations in the bladder which destroys residual urothelial cancerous cells (Kaufman, 2006; Kaufman et al., 2009; Konety et al., 2007). Due to cellular and physiological limitations posed by the urothelium as well as urine, it is not sufficient to simply administer cytotoxic formulations intravesically; there is a need for careful design of drug delivery systems that would be able to circumvent these barriers.

Some good reviews have been published that considered varieties of nanoparticles and nanotechnology for BC therapy and / or diagnosis (Chen et al., 2015; GuhaSarkar and Banerjee, 2010; Tomlinson et al., 2015) but some of the nanoparticulate systems discussed were developed over a decade ago and recent studies were not discussed fully in some of the articles. Moreover, formulation strategies that require adjunct equipment such as electromotive device assisted therapy 
(EMDA) and hyperthermia (HT) has not been widely embraced by urologists because of their complex delivery modalities (Barocas et al., 2012).

This review, therefore, will discuss briefly the pathophysiology, prevalence and staging of BC and will focus on advanced polymeric formulations investigated for $\mathrm{BC}$ management that have not been covered previously. Also, in vitro and in vivo models that are currently used for IDD studies will be discussed. The reviewed advanced drug carriers are categorised into four groups based on nonparticulate, particulate, composite systems of hydrogels and particles as well as liposomal drug carriers.

\section{Bladder Physiology}

\subsection{Structure of the bladder}

In order to carry out its urine storage and voiding functions, the bladder (Figure 2) can change volume although it remains almost spherical in shape (GuhaSarkar and Banerjee, 2010). The bladder wall is comprised of four layers: the urothelium, lamina propria, detrusor muscle, and serous (adventitia) layers (Konety et al., 2007). The urothelium acts as a permeability barrier and comprises of umbrella cells knitted together by tight junctions and enveloped by uroplakin plaques, mucin, intermediate and basal cell layers. These components prevent diffusion of pathogenic and toxic substances into the systemic circulation; their detailed functions have been discussed in the previous review (GuhaSarkar and Banerjee, 2010). Regulatory information emanating from the bladder lumen is transmitted by the urothelium to the surrounding tissues (myofibroblasts and musculature) via different neurotransmitters including adenosine triphosphate, adenosine and acetylcholine (Khandelwal et al., 2009). The urothelium is covered by a layer of glycosaminoglycans which limits the adherence of negatively charged drug carriers (Lewis, 2000). This also means that, systemic therapeutic agents for BC treatment cannot diffuse efficiently into the bladder (Soler et al., 2008). 


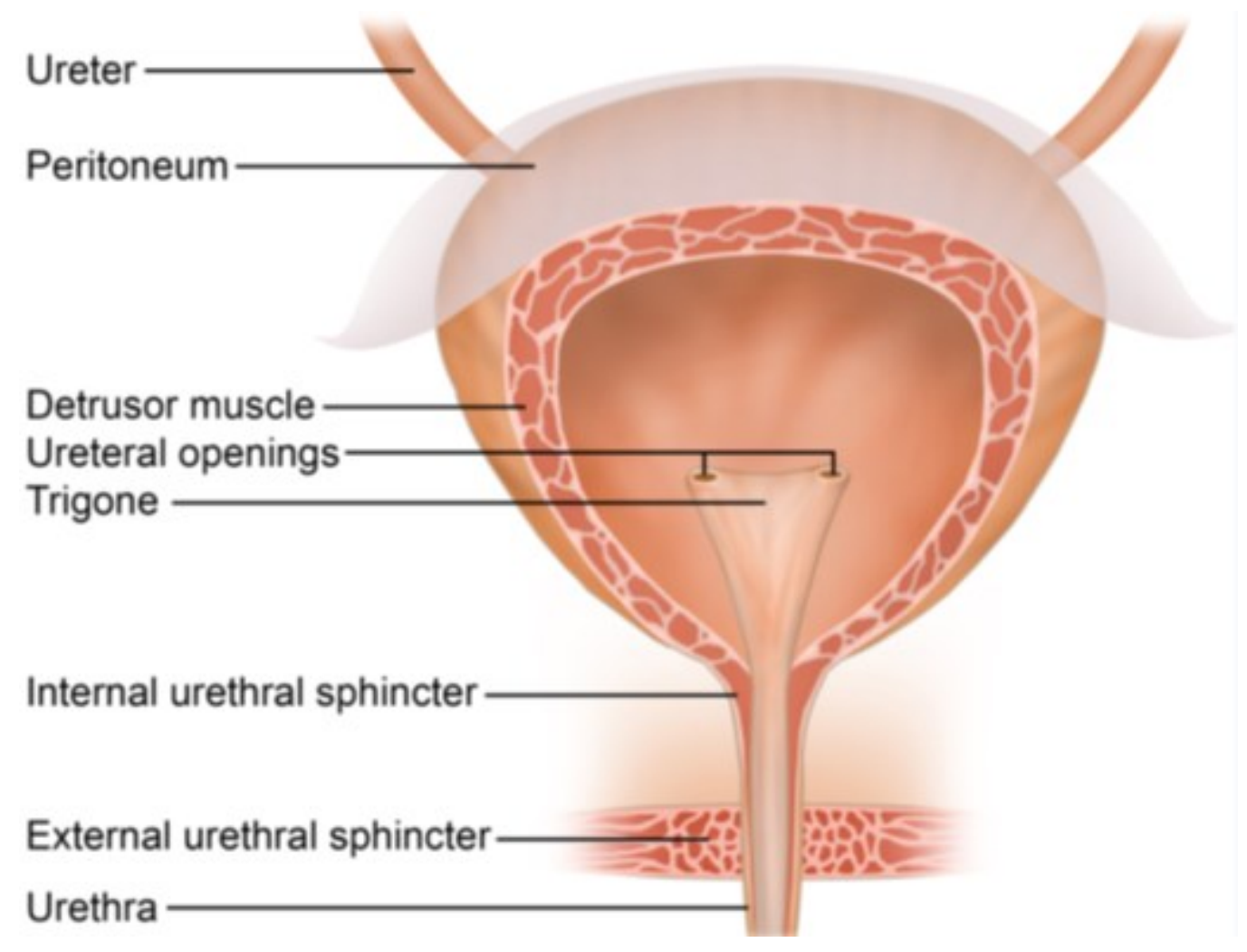

Figure 2: Schematic diagram showing various segments of the bladder. This image was designed and kindly provided by Ms Stephanie Bull.

\subsection{Urine Volume and Composition:}

The volume of urine in a human bladder is dependent on the sex, race and ethnicity of an individual but in the adult it averages around $350-450 \mathrm{~mL}$ when full (Gray, 2012) although the first sensation of urination occurs at around 150 to $200 \mathrm{~mL}$ of urine (GuhaSarkar and Banerjee, 2010). Urine voiding activity is regulated by the myovesical plexus within the bladder wall which produces a specific sensation when sufficient urine is present in the bladder and sends a voiding signal to the detrusor muscle which relaxes or contracts appropriately in order to regulate the extent and frequency of voiding (Khandelwal et al., 2009).

\section{Bladder Cancer}

\subsection{Genetic / Molecular expressions in Bladder Cancer}

Some of the genetic materials that are expressed in $\mathrm{BC}$ can be used as molecular targets to design effective therapies. For example, survivin detectable in the urine of BC patients (Smith et al., 2001) has been implicated in BC as it improves the survival rate of cancerous cells by preventing cell death 
(Swana et al., 1999). BC patients also are known to express particular mucins (MUC1 and MUC3) associated with bladder malignancies (Cardillo et al., 2000).

The natural immune system of the bladder is achieved through uroplakins, a group of proteins found at the apex of the umbrella cell membrane, namely UPIa, UPIb, UPII, and UPIIla. They induce bacterial death when infected. They also perform barrier functions along with tight junctions, where they prevent drug diffusion across the urine / bladder tissue interface (Kong et al., 2004; Wu et al., 1994; Yu et al., 1994). Changes in the glycosylation of uroplakins especially UPIII may depict advanced stages of $\mathrm{BC}$, in addition to clinical conditions such as urinary tract infections and interstitial cystitis (Kątnik-Prastowska et al., 2014).

Lewis X glycoantygen, sialyl-Tn (carbohydrate) and its degrading enzyme (sialyltransferase) are expressed on the urothelium and are markers for BC (Kątnik-Prastowska et al., 2014). Metabolomics of urine samples from $B C$ and non-BC subjects' revealed that biomarkers (lipid-metabolic products) such as arachidonite, palmitoyl sphingomyelin, lactate, adenosine and succinate are found in BC patients only (Wittmann et al., 2014). Chemokine ligand 1 (CXCL1), which modulates interaction between stroma and urothelium, in order to accelerate tumor progression and metastasis, is also expressed in urine samples of BC patients (Burnier et al., 2015).

\subsection{Stages of bladder cancer}

About $90 \%$ of BC cases are transitional cell carcinomas while squamous cell carcinomas occurs in 3 7\% patients and around 2\% have adenocarcinomas (Sharma, 2014). Usually, the urothelial layer of the bladder is initially affected by most BC types. The nearby lamina propria and muscular layer becomes involved as the tumor progresses. Afterwards, the lymph nodes or pelvic organs are also affected (Sharma, 2014). The metastatic stage arises when cancerous cells divide and spread to distant organs such as lungs, liver and bone marrow (Sharma, 2014).

The tumor stage defines the extent of disease progression (Bischoff and Clark, 2009); and the tumor node metastasis staging system developed by International Society of Urological Pathology in 1997 for BC classification is still being used by World Health Organization (WHO) (Moch et al., 2016). The American Joint Committee on Cancer TNM system categorises bladder cancer based on growth into the bladder wall $(T)$, spread to neighbouring lymph nodes $(\mathrm{N})$ and metastases $(\mathrm{M})$. Information from these categories is then used to evaluate the overall stage of the disease from stage 0 to IV (Table 1 ). 
Table 1: Bladder cancer stages. Information from taken from (Team, 2016)

\begin{tabular}{|l|l|l|}
\hline Category & Stage & Description, including tumor coverage \\
\hline Ta, N0, M0 & Stage 0a & Non-invasive papillary carcinoma - hollow centre of the bladder \\
\hline Tis, N0, M0 & Stage Ois & $\begin{array}{l}\text { Flat, non-invasive carcinoma (carcinoma in situ) - inner bladder } \\
\text { lining }\end{array}$ \\
\hline $\begin{array}{l}\text { T1,N0, M0 } \\
\text { N0, M0 }\end{array}$ & Stage I & Invasive - connective tissues beyond the urothelial lining \\
\hline $\begin{array}{l}\text { T3a, T3b, T4a, } \\
\text { N0, M0 }\end{array}$ & Stage III & $\begin{array}{l}\text { Invasive - fatty tissue region visible with microscope (T3a); readily } \\
\text { visible (T3b); spread to prostate, uterus and/or vagina (T4a) }\end{array}$ \\
\hline $\begin{array}{l}\text { T4b, N0, M0, } \\
\text { N1-N3, M1 }\end{array}$ & Stage IV & $\begin{array}{l}\text { Invasive / metastatic - Pelvic or abdominal wall (T4b); single pelvic } \\
\text { Iymph node (N1); } \geq 2 \text { lymph nodes (N2); iliac arterial lymph nodes } \\
\text { (N3); beyond the bladder to distant sites like bones, liver or lungs }\end{array}$ \\
\hline
\end{tabular}

Note: $\mathrm{NO}$ and $\mathrm{MO}$ denotes that lymph nodes and distant sites (metastatic tumors) were not affected, respectively

Eble et al graded BCs based on cell morphology into $G 1, G 2$ and $G 3$, with $G 1$ being the most well differentiated, while $\mathrm{G} 3$ is the least differentiated $\mathrm{BC}$ having the greatest risk of progression (Eble et al., 2004). Recently, WHO proposed a new grading classification for BC based on improved knowledge of its pathology and genetics (Figure 3), where "urothelial dysplasia" and "urothelial proliferation of uncertain malignant potential" were included as well defined forms of non-invasive urothelial lesions (Moch et al., 2016). 


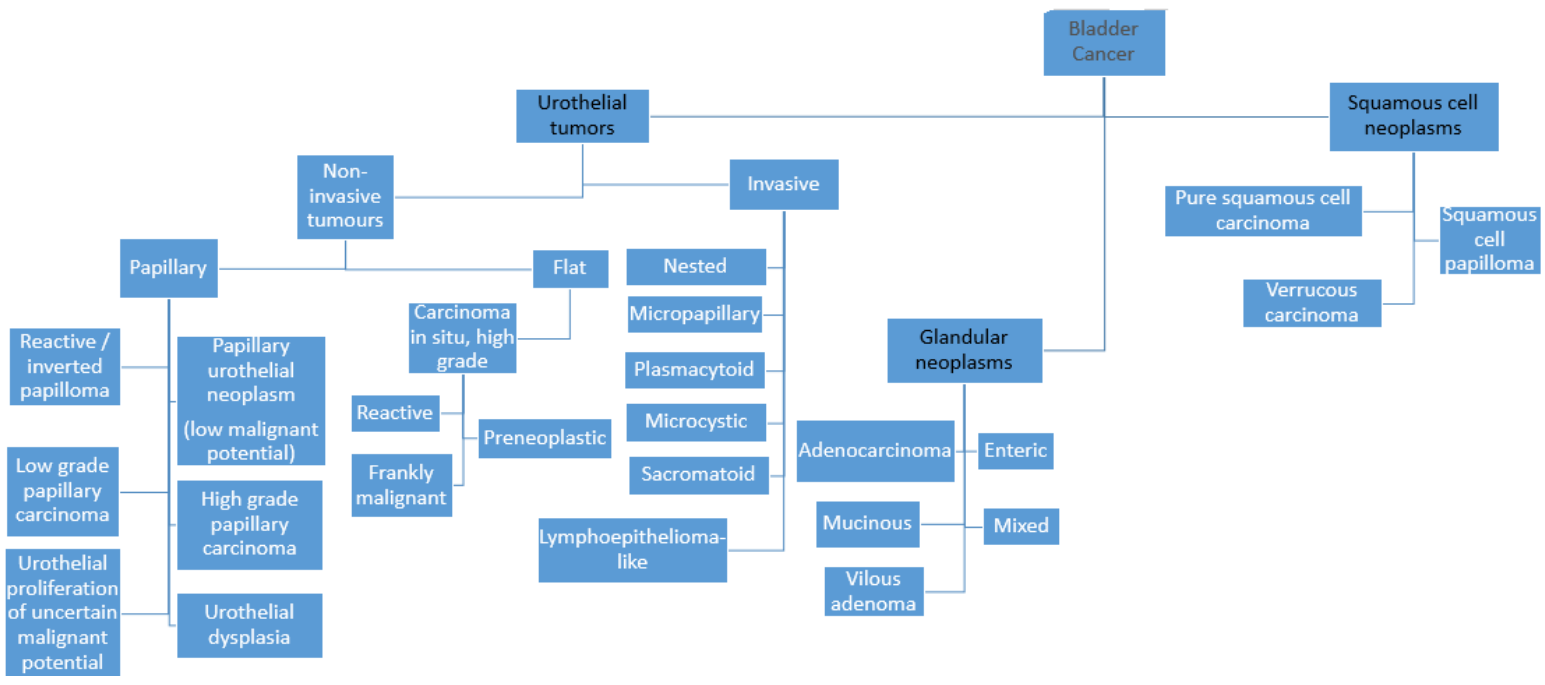

Figure 3: The 2016 WHO Classification of Bladder Cancer (details extracted and presented in a different format) (Moch et al., 2016)

\section{Management of bladder cancer}

BC treatment is dependent on the stage and severity of disease (Sharma, 2014). The UK National Institute for Health and Care Excellence (NICE) has produced guidelines regarding the diagnosis and treatment of BC. It recommends that both cystoscopy and urine cytology is needed in order to diagnose BC as cystoscopy alone may miss some tumours such as CIS (NICE, 2015). The extent of BC progression is identified using computer tomography (CT) or magnetic resonance imaging (MRI) techniques. NMIBC is initially treated by TURBT (Lerner and Au, 2008; NICE, 2015). Patients with a low risk of disease recurrence post-surgery may be followed up with cystoscopic surveillance alone, whilst those in the intermediate and high risk categories are treated with intravesical chemotherapy (mitomycin C) or immunotherapy (BCG) (Lerner and Au, 2008). The latter triggers an immune response that ensures future recognition of $B C$ cells, and this treatment has been proven to prevent progression in about $85 \%$ of $B C$ cases.

\section{Intravesical Formulations}

The effectiveness of bladder cancer therapeutic dosage forms depends on their ability to overcome the urothelium as well as the drug having suitable physicochemical properties such as molecular weight ( $\leq 200 \mathrm{Da}$ ), water or lipid solubility, aqueous / organic phase partition coefficient (-0.4 to -0.2 or -7.5 to -8.0 ) and pH 6 to 7 (GuhaSarkar and Banerjee, 2010). Also, the surface charge of drug carriers influences their cellular uptake, for example, positively charged nanoparticles (NPs) are taken up by cells and readily absorbed into tissues in preference to anionic or neutral NPs (He et al., 
2010; B. Kim et al., 2010). The uptake of such drug cargos may be prevented by poor interaction with biorecognitive moieties that facilitate cellular internalisation (Khandelwal et al., 2009); in addition to lack of electrostatic interaction between oppositely charged carrier and bladder mucosa.

\subsection{Conventional formulations}

The surgical implantation of drug loaded gels into $B C$ patients was expensive and unacceptable (Singh and Lee, 2014). So, local drug delivery using drug instillation via a catheter was adopted which permits easy bladder accessibility and avoids surgery (Shen et al., 2008). The usual volume of drug formulation instilled intravesically is approximately $50 \mathrm{~mL}$ (Senyigiti et al., 2015) and micturition is prevented for at least 1-2 $\mathrm{h}$ for effective drug transport into the underlying cancerous tissues (Tyagi et al., 2006). Nevertheless, the instilled drug becomes diluted due to residual urine which is often present in the human urinary bladder and/or is washed out prematurely (Grabnar et al., 2006). These limitations mean that frequent catheter insertion, decreased dosing interval and eventual irritation of the urethral lining and possible urinary tract infection are possible complications of intravesical drug delivery (Martin et al., 2014). Also, conventional drug carriers such as microspheres (Bogataj et al., 1999; Le Visage et al., 2004) and gelatin nanoparticles (Lu et al., 2004b) display poor drug loading and uncontrolled drug release profiles.

\subsection{Advanced formulations}

Hydrophilic drugs are readily soluble in the aqueous urine medium of the bladder but their permeability and cellular uptake is limited due to the lipophilic nature of the urothelial tissues. Thus, chemical enhancers such as dimethyl sulfoxide (DMSO) have been used to improve the cellular uptake of $\mathrm{BC}$ chemotherapeutics such as doxorubicin and cisplatin into malignant bladder tissues (Giannantoni et al., 2006). However, their use is now less favourable because of unwanted sideeffects such as frequent and painful urination (GuhaSarkar and Banerjee, 2010). Also, hydrophobic drugs such as paclitaxel formulated with DMSO for improved solubility and urothelial permeability are associated with painful sensation post intravesical instillation (Parkin et al., 1997).

Therefore, smart drug carriers were developed to improve the solubility of lipophilic drugs; urothelial permeability of hydrophilic drugs; urothelial adhesion of drug carriers as well as drug uptake / permeation into malignant tissues for prolonged periods of time. They include amphiphilic copolymer based solubilised systems (Tamura et al., 2015), surface modified particulate systems (Cook et al., 2015; Lu et al., 2015; Martin et al., 2014, 2013; Neutsch et al., 2013; Zhang et al., 2014), and composite particulate and hydrogel systems (Lin et al., 2014; Men et al., 2012; Senyigiti et al., 2015; Zhang et al., 2013)(Table 2). 
Table 2: Overview of intravesical formulations explored for bladder cancer therapy

\begin{tabular}{|c|c|c|c|c|}
\hline Class & Agent & Material & Dosage form & References \\
\hline $\begin{array}{l}\text { Amphiphilic } \\
\text { copolymer } \\
\text { based } \\
\text { solubilised } \\
\text { systems }\end{array}$ & Paclitaxel & $\begin{array}{l}\text { Poly (2-methacryloyloxyethyl } \\
\text { phosphorylcholine-co-n- } \\
\text { butylmethacrylate) diblock } \\
\text { copolymer (30mol\% MPC } \\
\text { unit: } 70 \text { mol\% hydrophobic } \\
\text { BMA unit) }\end{array}$ & $\begin{array}{l}\text { Ionotropic } \\
\text { solution }\end{array}$ & $\begin{array}{l}\text { (Tamura et } \\
\text { al., 2015) }\end{array}$ \\
\hline \multirow{7}{*}{$\begin{array}{l}\text { Surface } \\
\text { modified } \\
\text { particulate } \\
\text { systems }\end{array}$} & Belinostat & PGON, PLGA & Nanoparticles & $\begin{array}{l}\text { (Martin et } \\
\text { al., 2013) }\end{array}$ \\
\hline & Doxorubicin & $\begin{array}{l}\text { B-cyclodextrin, mesoporous } \\
\text { silica }\end{array}$ & Nanoparticles & $\begin{array}{l}\text { (Zhang et } \\
\text { al., 2014) }\end{array}$ \\
\hline & $\begin{array}{l}\text { Survivin } \\
\text { SiRNA }\end{array}$ & Chitosan, PLGA & Nanoparticles & $\begin{array}{l}\text { (Martin et } \\
\text { al., 2014) }\end{array}$ \\
\hline & $\begin{array}{l}\text { Stearoyl } \\
\text { Gemcitabine }\end{array}$ & $\begin{array}{l}\text { Wheat Germ Agglutinin, } \\
\text { PLGA }\end{array}$ & Microparticles & $\begin{array}{l}\text { (Neutsch et } \\
\text { al., 2013) }\end{array}$ \\
\hline & Doxorubicin & $\begin{array}{l}\text { Copolymer of 2- } \\
\text { (acetylthio)ethylacrylate and } \\
\text { 2-hydroxyethylmethacrylate }\end{array}$ & $\begin{array}{l}\text { Thiolated } \\
\text { Microgels }\end{array}$ & $\begin{array}{l}\text { (Cook et al., } \\
2015)\end{array}$ \\
\hline & Docetaxel & $\begin{array}{l}\text { Amine functionalized } \\
\text { polyacrylamide }\end{array}$ & Nanogels & $\begin{array}{l}\text { (Lu et al., } \\
2015 \text { ) }\end{array}$ \\
\hline & $\begin{array}{l}\text { 10- } \\
\text { hydroxycam } \\
\text { ptothecin }\end{array}$ & $\begin{array}{l}\text { Poly (L-lysine)-poly (L- } \\
\text { phenylalanine-co-L-cysteine) }\end{array}$ & Nanogels & $\begin{array}{l}\text { (Guo et al., } \\
2016 \text { ) }\end{array}$ \\
\hline $\begin{array}{l}\text { Composite } \\
\text { particulate } \\
\text { and hydrogel } \\
\text { systems }\end{array}$ & Adriamycin & $\begin{array}{l}\text { Poloxamer } 407 \text { (triblock } \\
\text { copolymer), sodium } \\
\text { hydrogen carbonate, HPMC, } \\
\text { Human Serum Albumin }\end{array}$ & $\begin{array}{l}\text { Floating } \\
\text { hydrogel- } \\
\text { nanoparticle } \\
\text { system }\end{array}$ & $\begin{array}{l}\text { (Lin et al., } \\
\text { 2014) }\end{array}$ \\
\hline
\end{tabular}




\begin{tabular}{|c|c|c|c|c|}
\hline & $\begin{array}{l}\text { Bacillus } \\
\text { Calmette- } \\
\text { Guérin }\end{array}$ & $\begin{array}{l}\mathrm{CS}, \beta \text {-glycerophosphate, } \\
\text { magnetite }\end{array}$ & $\begin{array}{l}\text { Mucoadhesive } \\
\text { nanoparticle - in } \\
\text { situ gelling } \\
\text { system }\end{array}$ & $\begin{array}{l}\text { (Zhang et } \\
\text { al., 2013) }\end{array}$ \\
\hline & Deguelin & $\begin{array}{l}\text { DOTAP, monomethoxy poly } \\
\text { (ethylene glycol)-poly ( } \varepsilon \text { - } \\
\text { caprolactone) NP + Pluronic } \\
\text { F127 hydrogel }\end{array}$ & $\begin{array}{l}\text { Mucoadhesive } \\
\text { nanoparticle - in } \\
\text { situ gelling } \\
\text { system }\end{array}$ & $\begin{array}{l}\text { (Men et al., } \\
\text { 2012) }\end{array}$ \\
\hline & $\begin{array}{l}\text { Gemcitabine } \\
\mathrm{HCl}\end{array}$ & $\begin{array}{l}\text { Chitosan-thioglycolic acid } \\
\text { conjugate based NPs + } \\
\text { chitosan gel / Poloxamer gel }\end{array}$ & $\begin{array}{l}\text { Thiolated } \\
\text { nanoparticle- gel } \\
\text { / in situ gelling } \\
\text { system }\end{array}$ & $\begin{array}{l}\text { (Senyigiti et } \\
\text { al, 2015) }\end{array}$ \\
\hline $\begin{array}{l}\text { Liposomal } \\
\text { systems }\end{array}$ & Paclitaxel & $\begin{array}{l}\text { Soya phosphatidylcholine, } \\
\text { gellan gum }\end{array}$ & $\begin{array}{l}\text { Liposomes / ion- } \\
\text { triggered gelling } \\
\text { system }\end{array}$ & $\begin{array}{l}\text { (GuhaSarkar } \\
\text { et al., 2017) }\end{array}$ \\
\hline
\end{tabular}

\subsubsection{Amphiphilic copolymer based solubilised systems}

Solubilised systems are isotropic solutions of a substance in a state of thermodynamic stability generated by dispersing the sparingly soluble substance in an amphiphilic material (Tadros, 2013). Cremophor is conventionally used to improve the solubility of paclitaxel (PTX-CrEL) in the physiological fluid but its use is limited by adverse effects as well as by reduced drug permeation across the mucosal lining due to drug entrapment in polymeric micelles (Knemeyer et al., 1999). However, the amphiphilic copolymeric delivery system, poly(2-methacryloyloxyethyl phosphorylcholine-co-n-butyl methacrylate (PMB30W) has been proven to be non-toxic with improved paclitaxel uptake into mammalian cell lines during in vitro studies (Goda et al., 2010; Wada et al., 2007). PTX-30W was formulated by solubilising paclitaxel (PTX) in PMB30W in order to improve its aqueous solubility, safety and antitumor activity (Tamura et al., 2015). In vitro studies using MBT-2 BC cells to compare cytotoxicity of PMB30W and Cremophor ( $\mathrm{CrEL}$ ) to BC cells showed that PMB30W (1\%) displayed no toxic effect to the cells while dose associated toxicity was reported with $\mathrm{CrEL}$ after $72 \mathrm{~h}$ of instillation. This was confirmed by the lactate dehydrogenase (LDH) activity assay, detecting $0 \%$ and $65 \% \mathrm{LDH}$ release for PMB30W and $\mathrm{CrEL}$, respectively, in the same study (Tamura et al., 2015). 
The ability of an orthotopic bladder cancer mouse model (implanted with MBT-2 BC cells) to mimic the human BC environment has been confirmed in several studies (Kikuchi et al., 2007; Matsushima et al., 2011). This orthotopic model of $B C$ was established through transurethral implantation of MBT-2 BC cells into mice. During ex vivo studies, mice were treated with various formulations (50 $\mu \mathrm{L}$ of $2 \mathrm{mg} / \mathrm{mL}$ PBS, PTX-30W and PTX-CrEL) at predetermined time intervals and killed after 22 days to determine the degree of tumor growth or regression (Tamura et al., 2015). It was shown that PTXMBA improved tumor regression (more than 2 folds) in comparison with PTX-CrEL (Tamura et al., 2015). Also, some of the mice were sacrificed $30 \mathrm{~min}$ post intravesical drug instillation and the degree of drug uptake into tumour tissues quantified using liquid chromatography using a tandem mass spectrometer, was shown to be remarkably lower in PTX-CrEL than in the PTX-30W group of mice $(4.905 \pm 2.412 \mu \mathrm{g} / \mathrm{g}$ vs $7.719 \pm 3.274 \mu \mathrm{g} / \mathrm{g})$. This revealed improved selectivity of the novel paclitaxel carriers for malignant tissues (Tamura et al., 2015). However, studies related to the resistance of the delivery system to urine dilution or wash-out were not evaluated and periodic urine voiding and residual urine in the bladder may have affected product performance. Also, drug release studies were not carried out, thus the pattern of drug release is unknown. This makes it difficult to ascertain that the drug would be released in a controlled manner, which is a critical parameter for improved formulations that would reduce dosing frequency.

\subsubsection{Surface modified particulate systems}

\subsubsection{Lectin modified particulate systems}

Glycans and lectins are biological entities that are sensitive and responsive to bacterial and malignant invasion by destroying them through endocytosis, where they interact and adhere onto mannose receptors (Bies et al., 2004; Haltner et al., 1997; Yi et al., 2001). It is anticipated that lectins will be useful for malignant conditions associated with the bladder because they attach to the distal portion of Escherichia coli pili and destroy the E. coli in bacterial urinary infections (Dhakal et al., 2008). Also, urothelial cellular uptake of plant lectin, like wheat germ agglutinin (WGA, 36 kDa), in pigs and humans, suggested that biologics may be delivered intravesically, as lectins are readily recognised by the glycol-proteins and lipids of the urothelium and facilitate cellular uptake of a bioconjugate (Neutsch et al., 2011). Neutsch and co-workers surface-functionalised fluorescently labelled bovine serum albumin ( $\mathrm{FBSA}$ ) with WGA units and this modification influenced the urothelial cell (SV-HUC-1) adhesive and invasive potential of the fBSA / WGA bioconjugate (Neutsch et al., 2012). Their cytoadhesive features were greatest when the total number of targeting ligands was three and such features did not increase further for bioconjugates with 4-6 WGA units (Neutsch et al., 2012). This glycan-modulated interaction was critical for internalization of the drug carrier (> 175 $\mathrm{kDa}$ ) within less than 60 minutes, with more than $40 \%$ of drug taken up via endocytosis (Neutsch et 
al., 2012). The unchanged extent of cell adhesive properties with increased WGA units ( $\geq 3$ ) may be due to some of their recognitive domains being sterically hindered from binding to glycosylated urothelial cell membranes (Neutsch et al., 2012). WGA metabolism after fBSA release might have taken place via lysosome degradation (Neutsch et al., 2012).

Stearoyl gemcitabine (GEM- $\mathrm{C}_{18}$ ) loaded PLGA microparticles (MPs) surface modified with WGA or human serum albumin (HSA), WGA-GEM-C 18 -PLGA MPs or HSA-GEM-C 18 -PLGA MPs were explored for IDD (Neutsch et al., 2013). In vitro studies using cancerous and non-malignant cell monolayers showed that the WGA-GEM- $\mathrm{C}_{18}$-PLGA MPs had better cellular uptake, internalization and cytostatic action than HSA-GEM-C 18 -PLGA MPs and unmodified MPs within 3 mins of instillation. WGA-GEM$\mathrm{C}_{18}$-PLGA MPs also had a two-fold greater affinity towards malignant cell lines than healthy cells. The fluorescently labelled drug loaded WGA modified MPs and HSA based MPs required a contact time of 30 mins and 120 mins, respectively, to impart cytotoxic activity on low grade cancerous cell lines using fluorescence microscopy (Neutsch et al., 2013). WGA-GEM-C $\mathrm{C}_{18}$-PLGA MPs were more resistant to wash-off by artificial urine, which allowed for superior retention of cytostatic effect ( $78 \pm 12 \%)$ compared to free prodrug but the degree of cell inhibitory potential of the latter in the presence of urine was not defined (Neutsch et al., 2013). There was no significant difference in the sustained release effect (after 120 mins) for the three formulations (WGA- , HSA-modified and unmodified PLGA MPs), which could be attributed to the inability of the study design to simulate washout features of the urinary bladder. The WGA-modified MPs also had low drug release of $13.2 \pm 1.8 \%$ after 5 days with most of the drug retained within the particle matrix. However, studies of bromodeoxyuridine antimetabolic activity (that connotes duration of drug action) suggested that WGA based particles require lower dose than free drug for achieving a particular degree of prolonged action (Neutsch et al., 2013). Also, a cell proliferation assay suggested better antiproliferative properties for drug loaded surface modified particles than free drug (Neutsch et al., 2013).

Overall, the optimisation and translation of this strategy to the clinic may be limited by the relatively high cost of manufacturing associated with the processing in terms of time and materials required for isolation and purification of the bioconjugate of interest. The bioconjugate size may be heterogenous resulting in immunogenic and adverse reactions. However, the authors did not envisage such formulation constraint.

Recently, Apfelthaler et al evaluated a bioconjugate, WGA conjugated to fluorescein cadaverine (FC) labelled poly(L)glutamic acid (PGA) (WGA/FC-PGA), for bladder cancer theranostic application (Apfelthaler et al., 2017). PGA may improve the solubility of the hydrophobic agents while WGA 
favours the selective uptake of bioconjugate into malignant bladder tissues by interacting selectively with the glycocalyx components ( $\mathrm{N}$-acetyl-D-glucosamine and sialic acid) of BC cells (Wright and Kellogg, 1996). FC helps to track transport of the drug carrier into the cancerous cell endosome and/or lysosome. They confirmed earlier findings by Neutsch's group (Neutsch et al., 2013, 2012) that the presence of biorecognitive moieties like WGA was critical for improved cellular uptake and internalization of bioconjugates into BC cells. Flow cytometry was used to evaluate the cell-binding ability of WGA/FC-PGA. Size exclusion chromatography was used to purify the synthesized bioconjugate and isolate biorecognitive fractions. Conjugate A (160 kDa) fraction, obtained with 60 to $80 \mathrm{~mL}$ eluent, displayed superior cell binding efficiency relative to conjugates $B-D$ due to the presence of WGA conjugated FC-PGA system. Five FC molecules per PGA were critical for adequate trackability of the bioconjugate as it exhibited greater cell-induced relative fluorescence intensity than bioconjugate with $30 \mathrm{FC}$ per PGA. Conjugate $\mathrm{A}$ was found to be cytoadhesive at $4^{\circ} \mathrm{C}$ but become cytoinvasive at $37^{\circ} \mathrm{C}$ via active transport. On the other hand, conjugates $\mathrm{C}$ and $\mathrm{D}$ eluted around 90 $\mathrm{mL}$ and lacked both cell adhesive and uptake properties (Apfelthaler et al., 2017). There was no hydrophobic agents delivered within the scope of this study, though the authors acknowledged that their future studies will explore optimal drug loading that will not compromise the cell binding and uptake features of the bioconjugate. However, they noted that there is a need for conjugate $A$ (the most promising bioconjugate) to replicate a similar cytoinvasive and cytoadhesive profile when hydrophobic theradiagnostic agents are loaded.

\subsubsection{Mucoadhesive delivery systems}

Over the last decade, researchers have intensified efforts towards investigating materials with ability to adhere readily to mucosal surfaces because they can prolong contact time between dosage form and diseased site, which is desirable for intravesical formulations (Cook et al., 2015; Khutoryanskiy, 2011; Lu et al., 2004a; Senyigiti et al., 2015). Due to their successful applications for other transmucosal routes of administration such as buccal, ocular and vaginal (Bonengel and BernkopSchnürch, 2014), mucoadhesive systems have also been explored for intravesical delivery to enhance drug bioavailability and duration of action (Barthelmes et al., 2012; Cook et al., 2015; Men et al., 2012; Zhang et al., 2013, 2014).

\subsection{Cationic particulate systems}

Poly[D, L-lactide-co-glycolide] (PLGA) nanoparticles have been widely used for biomedical applications because of their biocompatibility, biodegradability, ease of modification with polymers and peptides (Cheng and Saltzman, 2011; Fahmy et al., 2005), ability to protect encapsulated biologics or therapeutics from degradation during transit, as well as the possibility for controlled 
release of loaded drugs (Anthony et al., 2005; Cu et al., 2011; Khan et al., 2004). Poly(guanidinium oxanorbornene) (PGON) is a non-toxic synthetic polymer which is comprised of cationic guanidinium groups and acts similarly like a peptide based cell penetration enhancer (Hennig et al., 2008). Martin et al explored surface functionalization of PLGA nanoparticles modified with a urothelial cell penetrating polymer such as PGON to improve aqueous solubility, urothelial cellular uptake, internalization, cytotoxic effect, and duration of action of lipophilic drugs such as belinostat, an histone deacetylase inhibitor (Martin et al., 2013). Belinostat promotes hyperacetylation (Martin et al., 2013) with intrinsic $I C_{50}$ in bladder and prostate cancer cells within the range of 1 to $10 \mu \mathrm{M}$ (Buckley et al., 2007; Qian et al., 2008); and inhibits BC progression to its metastatic and aggressive forms. All PLGA nanoparticles were 140-160 nm but PGON-modified PLGA nanoparticles (NPBelinostat-PGON) had superior drug loading relative to the unmodified (NP-Belinostat) and biotinylated chitosan conjugated nanoparticles (NP-Belinostat-Chit) by 3.3- and 6.8-folds, respectively (Martin et al., 2013). Ex vivo studies of fluorescently labelled NP-Belinostat-PGON using human ureter as well as in vivo studies with mouse bladder suggested that the uptake of NPBelinostat-PGON was ten times greater than that of unmodified nanoparticles (Martin et al., 2013). PGON improved urothelial uptake of nanoparticles by interaction with a negatively charged urothelial surface coated with glycosaminoglycan, or opening tight junctions of the urothelium. This facilitated drug transport across the urothelial membrane into underlying tissues (Martin et al., 2013). The in vivo cytotoxic effect of PGON-PLGA nanoparticles was tested using a xenograft murine model generated from the UM-UC-3R human BC cell line. Tumor growth was not significant after 11 days of treatment for NP-Belinostat-PGON, whereas the volume of tumors treated with unmodified PLGA nanoparticles and drug-free PGON-PLGA nanoparticles increased by at least two fold relative to tumors treated with NP-Belinostat-PGON. After 21 days, the volume of tumors treated with NPBelinostat and NP-Blank-PGON had increased by $77 \%$ and $71 \%$, respectively, relative to NPBelinostat-PGON treated tumors (Martin et al., 2013). The burst release profile of the novel drug carrier was evident by Histone $\mathrm{H} 4$ hyperacetylation occurring in RT-4 (non-invasive) and T-24 (highly invasive with metastatic tendency) cell lines within 30 mins following the instillation of NPBelinostat-PGON, and the protein expression was sustained for 3 days (Martin et al., 2013). Thus, a lower dose of the NP-Belinostat-PGON may be used to achieve the same therapeutic index observed with free belinostat (Martin et al., 2013).Though the degree of tumor regression by the PGON surface decorated PLGA nanoparticles may correlate with their extent of cellular uptake and drug release, the authors have not quantified the amount of belinostat that was taken up for the modified and unmodified nanoparticles. This information would be useful for determining dosage regimen for $\mathrm{BC}$ treatment using this drug carrier. 
In a later studies, Martin et al showed that PLGA nanoparticles functionalised with low molecular weight chitosan (CH) , 2.5 or $20 \mathrm{kDa}$ (CH2.5-PLGA or CH20-PLGA) were able to adhere onto urothelial surface and enhance the uptake of larger therapeutic agents like survivin siRNA (Martin et al., 2014). Survivin siRNA expression within urothelial cancerous cells enhanced destruction of survivin mRNA responsible for preventing death of cancerous cells. In vitro release studies showed the encapsulation efficiency of the nanoparticles modified with chitosan was superior compared to unmodified nanoparticles (70 vs $60 \%$ ). CH2.5-PLGA nanoparticles demonstrated a superior burst release profile relative to $\mathrm{CH} 20$-PLGA. Also, the $\mathrm{CH} 20$ decorated carrier displayed 10 -fold lower siRNA release than $\mathrm{CH} 2.5$-PLGA nanoparticles over 13 days. During ex vivo studies, $\mathrm{CH} 20-\mathrm{PLGA}$ and CH2.5-PLGA nanoparticles displayed improved cellular uptake into UM-UC-3 BC cells in comparison with control PLGA nanoparticles, in the magnitude of 5-10 fold and 4-9 fold, respectively, within 120 mins of incubation (Martin et al., 2014). During in vivo mice studies, bladder uptake was up to 14fold and 9-fold greater for CH20-PLGA and CH2.5-PLGA nanoparticles, respectively, compared to the control formulations (Martin et al., 2014). However, CH20-PLGA nanoparticles entrapped greater amounts of siRNA, in addition to forming bulkier surface groups, which prevented their release and bioactivity (Martin et al., 2014).

Thus $\mathrm{CH}$ 2.5-PLGA NPs may be desirable for therapy where fast onset of action is needed followed by a sustained release profile over a period of time. Moreover, the amount of drug taken up into bladder tissues was sufficient to reduce mRNA expression and promote tumor regression. The varied physicochemical interaction between the surface of carriers and the urothelial membrane is responsible for the different degree of tumor regression, sustained release, and duration of action observed. Their findings indicated that chitosan chain length used for surface modification influenced the carrier's drug loading, release, and cellular uptake behaviour.

\subsection{Thiolated particulate systems}

Some hydrophilic polymers such as chitosan are intrinsically mucoadhesive due to its cationic aminogroups which promote interaction with mucin (Barthelmes et al., 2011a; Sogias et al., 2008; Van der Lubben et al., 2001). Nevertheless, functional groups such as thiols (Barthelmes et al., 2011b; Bernkop-Schnürch and Greimel, 2005), acrylates (Brannigan and Khutoryanskiy, 2017; DavidovichPinhas and Bianco-Peled, 2011), maleimide (Tonglairoum et al., 2016) and catechols (Xu et al., 2012) have been explored to chemically modify polymers in order to improve their mucoadhesion. Irmukhametova et al reported the synthesis of thiolated nanoparticles using self-condensation of 3mercaptopropyltrimethoxysilane (Irmukhametova et al., 2011), which were subsequently used by 
Mun et al (Mun et al., 2016) to study retention on porcine bladder surface. Thiol-ene click chemistry involving interactions between pentaerythritol tetraacrylate and tetrakis (3-mercapto-propionate) were employed by Štorha and co-workers to produce thiolated nanoparticles (Štorha et al., 2013) that were shown to be adhesive to porcine bladder mucosa. However, these nanoparticles (Irmukhametova et al., 2011; Štorha et al., 2013) have not been explored for formulation of anticancer agents for intravesical BC therapy.

Zhang and co-workers generated thiol-functionalised cyclodextrin based mesoporous silica nanoparticles (MSNPs-CD-( $\left.\mathrm{NH}_{2}\right)-\mathrm{SH}$ ) for potential BC treatment and reported that they possess superior mucoadhesion compared to hydroxyl and amino-functionalised NPs [MSNPs-CD-(OH) and MSNPs-CD-( $\left.\mathrm{NH}_{2}\right)$ ] during mucin-nanoparticles interaction studies (Zhang et al., 2014). In vitro MTT cytotoxic testing on UMUC3 BC cells showed that the $\mathrm{IC}_{50}$ for doxorubicin loaded thiolated NPs (DoxMSNPs-CD-(NH 2$)-S H)$ and free doxorubicin were $3.92 \pm 1.06 \mu \mathrm{gL}^{-1}$ and $0.45 \pm 0.05 \mu \mathrm{g} \mathrm{mL}^{-1}$, respectively (Zhang et al., 2014). The gradual release of doxorubicin from the nanoparticulate formulation into the endosomes /lysosomes of the $\mathrm{BC}$ cells may be responsible for the $\mathrm{IC}_{50}$ of about $3.92 \mu \mathrm{g} \mathrm{mL}^{-1}$ reported for Dox- MSNPs-CD-( $\left.\mathrm{NH}_{2}\right)-\mathrm{SH}$. However, $\mathrm{IC}_{50}$ values for MSNPs-CD-(OH) and MSNPs-CD- $\left(\mathrm{NH}_{2}\right)$ also evaluated in the study, were not provided. Thus there were no means of establishing the cytotoxic superiority of doxorubicin loaded thiolated drug carriers over amino- and hydroxylated nanoparticles. Also, in vitro drug release studies revealed that doxorubicin was released faster (63\%) from thiolated nanoparticles deposited onto porcine bladder tissues incubated in simulated urine conditions $(\mathrm{pH} 6.1)$ relative to PBS $(\mathrm{pH} 7.4)$, with drug release of $13 \%$ after $48 \mathrm{~h}$ (Zhang et al., 2014). However, studies that use artificial urine may be more reliable as it is closest to the physiological environment of the bladder.

Cook et al, co-polymerised a thiol-bearing monomer, 2-(acetylthio)ethylacrylate (ATEA) with 2hydroxyethylmethacrylate (HEMA) using ethylene glycol dimethacrylate as a cross-linker (Figure 4) to generate 635-977 nm thiolated microgels (Cook et al., 2015). These microgels were found to exhibit high doxorubicin encapsulation efficiency (75-86\%), good colloidal stability, excellent bladder mucoadhesion as well as sustained drug release over $300 \mathrm{~min}$. Doxorubicin was released from the insoluble matrix through Fickian diffusion established from the Higuchi drug release model. 


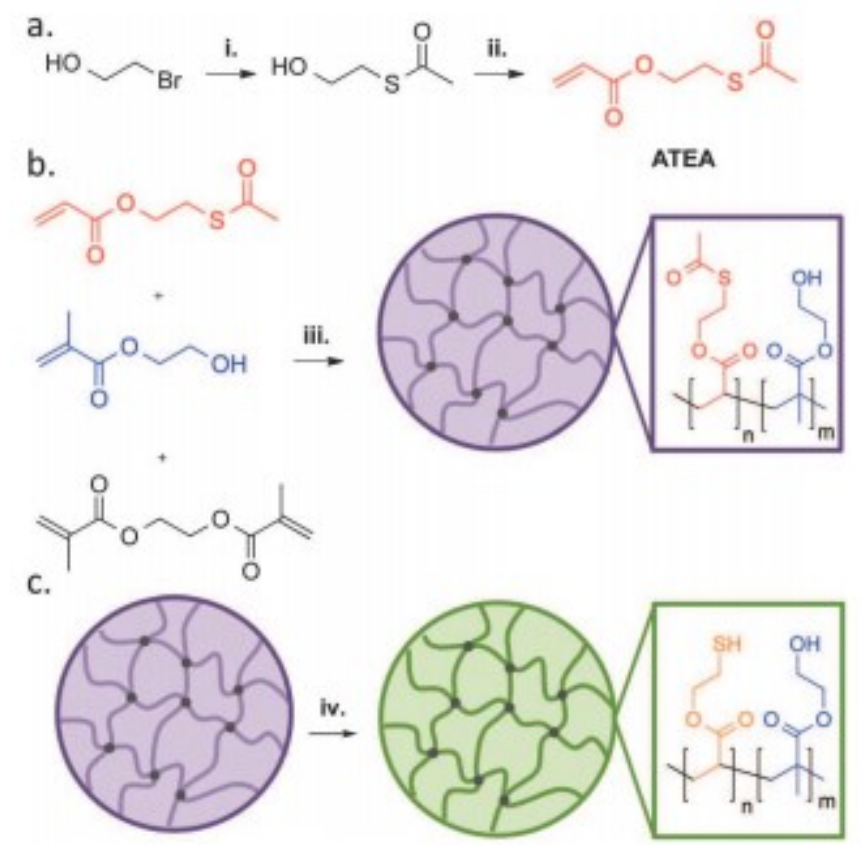

Figure 4: Synthesis of thiolated microgels: (a) Synthetic route to ATEA, a protected thiomonomer. (b) Polymerisation to form ATEA: HEMA copolymer microgels, displaying the pendant functionalities present. (c) Deprotection of ATEA using sodium thiomethoxide to yield thiolbearing microgels. (i) Potassium thioacetate, acetone, 24 h. (ii) Acryloyl chloride, trimethylamine, DCM, reflux, $24 \mathrm{~h}$. (iii) Ammonium persulfate, ethylene glycol dimethacrylate, water, $70^{\circ} \mathrm{C}, 6 \mathrm{~h}$. (iv) Sodium thiomethoxide, methanol, $30 \mathrm{~min}$. This figure is reproduced from Cook et al., (2015). Reproduced with permission from the Royal Society of Chemistry.

Also, the retention of doxorubicin loaded microgels on the bladder tissues was modulated by variation of the molar proportions of both monomers (ATEA \& HEMA) to generate microgels with desirable thiol content. For example, microgels with the greatest and least degree of thiolation were achieved with 80 mol\% and 30 mol\% ATEA, respectively (Cook et al., 2015). The former resisted wash off by artificial urine during ex vivo porcine bladder mucoadhesion studies compared with the latter. This may be associated with a greater amount of thiol groups forming covalent disulphide bridges with the cysteine-rich regions of urothelial mucins as mucosal adherence was independent of surface charge or polarity of carrier. The $30 \mathrm{~mol} \%$ and 80 mol\% ATEA / HEMA based microgels had capacity for loading up to $2.5 \mathrm{mg} \mathrm{mL}^{-1}$ and $2.7 \mathrm{mg} \mathrm{mL}^{-1}$ doxorubicin, respectively (Cook et al., 2015), which was greater than the therapeutic doses of doxorubicin (1-2 mg mL-1; 25-100 mL solution) (Amling, 2001; Lamm et al., 2005). However, future in vivo studies are desirable to facilitate further development of these drug carriers.

Cationic amine-functionalised polyacrylamide $\left(\mathrm{PAm}-\mathrm{NH}_{2}\right)$ based nanogels were investigated for intravesical delivery of docetaxel (Lu et al., 2015) due to their safety, mucoadhesive properties and 
sustained release potential. They were prepared as a lyophilized solid readily dispersible in water or phosphate buffer saline (PBS). These materials had high drug loading (>90\%) with an initial burst release within $9 \mathrm{~h}$ and a sustained release over 9 days when formulations were put in a dialysis membrane and drug release evaluated in artificial urine over predetermined time intervals (Lu et al., 2015). Docetaxel loaded functionalised carrier (DTX-Pam- $\mathrm{NH}_{2}$ ) displayed superior inhibition towards UMUC3 cells relative to T24 cells, with a minimum inhibitory concentration $\left({ }^{\prime} C_{50}\right)$ of $5.6 \mathrm{ng} / \mathrm{mL}$ vs $535.6 \mathrm{ng} / \mathrm{mL}$ ) over $4 \mathrm{~h}$ and the difference became more pronounced with an exposure time of $72 \mathrm{~h}$, with a calculated $I_{50}$ of $1.6 \mathrm{ng} / \mathrm{mL}$ and $11.6 \mathrm{ng} / \mathrm{mL}$, respectively. Also, the cellular uptake of fluorescently labelled DTX-Pam- $\mathrm{NH}_{2}$ nanogels into UMUC3 cells at $37^{\circ} \mathrm{C}$ was more pronounced than into the T24 cells in a concentration dependent manner. This finding was also confirmed in ex vivo studies using porcine bladder tissues, where persistent green fluorescence on bladder tissues suggested the adhesion of the fluorescent carrier onto bladder urothelium. The treatment of intact bladder urothelium with the novel formulation also confirmed its safety when analysed using scanning electron microscopy as it induced only mild disruption of the urothelial tissues (Lu et al., 2015). However, the preparation of nanogels was time-consuming as the preparation took about a week. Also, the amine functionalised surface may not have superior mucoadhesive features because its mode of interaction with the bladder mucosa would be via electrostatic attraction rather than covalent bonding which is stronger (Bernkop-Schnürch and Greimel, 2005).

Recently, Mun et al developed a new method for evaluating the retention of thiolated and PEGylated silica nanoparticles on porcine bladder epithelium during ex vivo studies as drug containing or blank formulations are being washed off using artificial urine (Mun et al., 2016). The parameter "Wash Out 50 " $\left(\mathrm{WO}_{50}\right)$ represented the volume of biological fluid (such as artificial urine) required to detach $50 \%$ of the adhered particulate carrier from a mucosal tissue. The in vitro studies also identified chitosan with superior $\mathrm{WO}_{50}$ value and mucoadhesive property relative to thiolated nanoparticles and dextran ( $89 \mathrm{~mL}$ vs $36 \mathrm{~mL}$ vs $7 \mathrm{~mL}$ ). The mucoadhesiveness of thiolated silica NPs was decreased with surface decoration with PEG and porcine bladder mucoadhesion reduced with increase in PEG molecular weight (5000 vs $750 \mathrm{Da}$ ) resulting in $\mathrm{WO}_{50}$ of $8 \mathrm{~mL}$ and $29 \mathrm{~mL}$, respectively (Mun et al., 2016).

Guo et al studied 10-hydroxycamptothecin (HCPT) loaded cationic cross-linked polypeptide (poly(Llysine)-poly (L-phenylalanine-co-L-cysteine) [PLL-P (LP-co-LC)] nanogels (HCPT/NG) for intravesical delivery. The poly(L-lysine) segment of the peptide is positively charged and interacts favourably with negatively-charged bladder mucosa while PLL-P (LP-co-LC) mimics cell penetrating peptides by promoting drug uptake into BC cells (Shin et al., 2014). The drug carrier had a particle size in a nanorange $(\approx 65 \mathrm{~nm})$; was positively charged $(+16.3 \pm 1.4 \mathrm{mV})$ as well as displayed good drug loading 
capacity and efficiency of 30.6 and $88.2 \%(w / w)$, respectively. Based on Confocal Laser Scanning Microscopic (CLSM) and microplate reading method of analysis, HCPT/NG was taken up into BC cells via endocytosis and drug was efficiently delivered into T24 cell nuclei within $6 \mathrm{~h}$, while the free drug formulation remained into the cytoplasmic region (Guo et al., 2016). During in vitro studies, T24 BC cells were treated with HCPT and HCPT/NG for $24 \mathrm{~h}$ and the cytotoxic effect of the formulations was investigated using MTT assay. The drug loaded nanogel showed greater cytotoxic effect than the free drug ( $\left(\mathrm{I}_{50}\right.$ values of $2.7 \mathrm{mg} / \mathrm{L}$ vs. $\left.7.9 \mathrm{mg} / \mathrm{L}\right)$. With the in vivo studies using orthotopic $\mathrm{BC}$ model, HCPT/NG demonstrated remarkably improved antitumor activity using flow cytometric cell analysis, with cell death occurring predominantly in the nanogel treated regions relative to that treated with free drug. In addition, the drug loaded nanogel exhibited superior tumor necrotic region (46.3 \pm $2.2 \%)$ relative to the cells exposed to free drug, up to 3.8 -fold increase. The in vivo biodistribution of the drug carriers was studied: six hours post treatment with nanogel and / or drug, the mice were sacrificed and their bladder and other major organs were excised, homogenised and evaluated by HPLC. The HCPT/NG were preferentially retained in the bladder and rarely in other organs, displaying 3.2-fold greater drug concentration in the bladder than that of the free drug-treated mice. This finding also correlates with the improved safety of the drug carrier due to targeted drug delivery, further confirmed by the insignificant changes in body weight throughout the studies (Guo et al., 2016). This drug carrier appears promising for the treatment of superficial BC. However, in vitro drug release and in vivo mucoadhesive profile of HCPT or HCPT/NG were evaluated using PBS. It will be more physiologically relevant if artificial urine was used instead of PBS.

\subsubsection{Composite system of nanoparticles and hydrogel}

Composite systems of nanoparticles and hydrogels were explored to combine the benefits of both formulations including improved drug loading, release, mucoadhesion and urothelial uptake. Hydrogels are three-dimensional hydrophilic or amphiphilic polymer networks, prepared by physical or chemical crosslinking of polymers. These materials exhibit excellent ability to retain water or biological fluids (Kopeček, 2007; Yu and Ding, 2008). They are soft, flexible and biocompatible; this makes them readily fabricated as building blocks for soft tissues (Khetan et al., 2013; Oommen et al., 2013; Rice et al., 2013). The physically cross-linked hydrogels are more readily eliminated after drug release and uptake into the urothelial tissues, than hydrogels prepared using covalently bonded polymers. However, a balance is required between prolonged duration of action and biodegradability so that covalently linked hydrogels do not cause any harm to the body. 
In situ gelling systems are liquid formulations with flowing tendency at room temperature and form gels at physiological environment in response to various stimuli such as $\mathrm{pH}$, enzymes or temperature. In recent years, temperature has become the commonly explored stimuli for such formulations (He et al., 2008; Kim and Park, 2002; Narendra and Lee, 20014), where sol-gel transition takes place at $37^{\circ} \mathrm{C}$ (within the body). It is desirable that dosage forms for mucosal delivery (including the intravesical route) have gelation temperature within the range of $30^{\circ} \mathrm{C}$ to $36^{\circ} \mathrm{C}$ (Choi et al., 1998). Over the last decade, biomedical researchers have explored these systems for drug / biomolecule delivery (Gong et al., 2012; Taylor et al., 2010; Wang et al., 2013) and tissue engineering (Niranjan et al., 2013) because they are readily manufactured, exclude use of organic solvents, administered in a minimally invasive mode, and provide sustained release (Supper et al., 2013).Their liquid consistency also allows their easy mixing with therapeutic agents before administration to a patient (Nguyen and Lee, 2010). Thus they have been employed for IDD, serving as drug reservoir, from where drug is released steadily over extended period of time.

\subsubsection{Floating Composite systems of NPs and hydrogels}

Adriamycin, an anthracycline antibiotic, is useful for reducing BC recurrence (Dalbagni, 2007) when administered intravesically after transurethral resection but its application was limited because it causes irritation and scarring of the bladder; additional problem with this drug is its rapid release (Eto et al., 1994). Floating strategies were used for oral formulations to improve residence time of drugs in the gastrointestinal tract (Pawar et al., 2011; Prajapati et al., 2013; Singh and Kim, 2000). Thus composite nanoparticle-hydrogel delivery system, with in situ gelling and floating potential within the bladder, was designed to serve as a drug depot to release adriamycin gradually and prevent urinary obstruction associated with the high viscosity of conventional non-mucoadhesive hydrogels (Lin et al., 2014). The safety of adriamycin has also been improved by formulating it as human serum albumin based nanoparticles (103 nm) that are loaded into Poloxamer 407 (P407) and hydroxypropyl methyl cellulose (HPMC) based thermosensitive gel (Lin et al., 2014). The P407 facilitated gelation through micellar packing and entanglements (Alexandridis and Hatton, 1995; Mortensen, 1993), while HPMC enabled attachment of the nanoparticles to the bladder wall and prolonged erosion of the gel which ensured sustained drug release. One of the components of this formulation (sodium hydrogen carbonate) enables the drug carrier to float in urine environment. It produces $\mathrm{CO}_{2}$ microbubbles in acidic medium which enables the hydrogel system to float, thereby preventing urinary obstruction (Lin et al., 2014). Nanoparticles with adriamycin formulated using P407 and HPMC were reported to undergo sol-gel transition within the shortest time possible, achieving gelation temperature (GT) of $10^{\circ} \mathrm{C}$ and gelation time (Gt) of 2 mins when evaluated at 
$37^{\circ} \mathrm{C}$, in comparison with other evaluated carriers (nanoparticles-adriamycin or non-floating hydrogel), with GT of 12 to $18^{\circ} \mathrm{C}$ and Gt of $2-5$ mins at $37^{\circ} \mathrm{C}$.

The amount of drug released into the urine of rats as well as the amount retained in their bladder following intravesical administration of a suspension of adriamycin nanoparticles and adriamycin loaded nanoparticles dispersed into in situ gelling liquid showed that the composite nanoparticleshydrogel system facilitated a controlled drug release with $81.87 \%$ drug released over $10 \mathrm{~h}$ compared to the nanoparticles (with loaded drug released instantly) (Lin et al., 2014). The in vitro and in vivo drug release studies did not correlate well due to the disparity in the volume of evaluation medium as well as hydrogel volume used. This is because the in vivo studies had to use hydrogel volume of $0.1 \mathrm{~mL}$ that can be accommodated in rat's bladder (volume of $\leq 1 \mathrm{~mL}$ ), while the in vitro studies used $400 \mathrm{~mL}$ release medium and hydrogel volume of $12 \mathrm{~mL}$ applicable to humans. However, to achieve this excellent retention effect urine needed to be acidified for the formulation to float. This may be less acceptable due to potential irritation of the bladder caused by low pHs (Lin et al., 2014). Thus floating in situ gelling drug carrier with sustained release profile at pH 6-7 (intrinsic pH of the bladder environment) would be worth investigating in the future.

\subsubsection{Non-floating, mucoadhesive composite systems of polymeric nanoparticles and hydrogels}

Some authors investigated delivery systems that form non-floatable gels in situ but made of materials that do not potentially obstruct urine elimination as they are flexible and steadily dissolved in urine over time, though mucoadhesive for sufficient length of time to allow for drug uptake into urothelial membranes.

Chitosan ( $\mathrm{CH}$ ) formulated with $\beta$-glycerophosphate disodium salt ( $\beta$-GP) is an example of physically cross-linked temperature-responsive gelling system (Figure 5) that has been evaluated by some researchers (Abdel-Bar et al., 2014; Khodaverdi et al., 2012; S. Kim et al., 2010). They suggested molecular mechanism for the gelation process in terms of increased electrostatic repulsion between chitosan macromolecules in the presence of negatively charged B-GP which also stabilise the resultant hydrogel system as well as chitosan intermolecular hydrophobic and hydrogen bonds (Lavertu et al., 2008; Qiu et al., 2011). It was suggested by Supper and co-workers (Supper et al., 2013) that these molecular interactions have not explained the influence of temperature on the gelation process, despite the fact that some authors (Patois et al., 2009; Schuetz et al., 2008) have established the role of polyol moiety of gelling material in their thermo-sensitivity. 


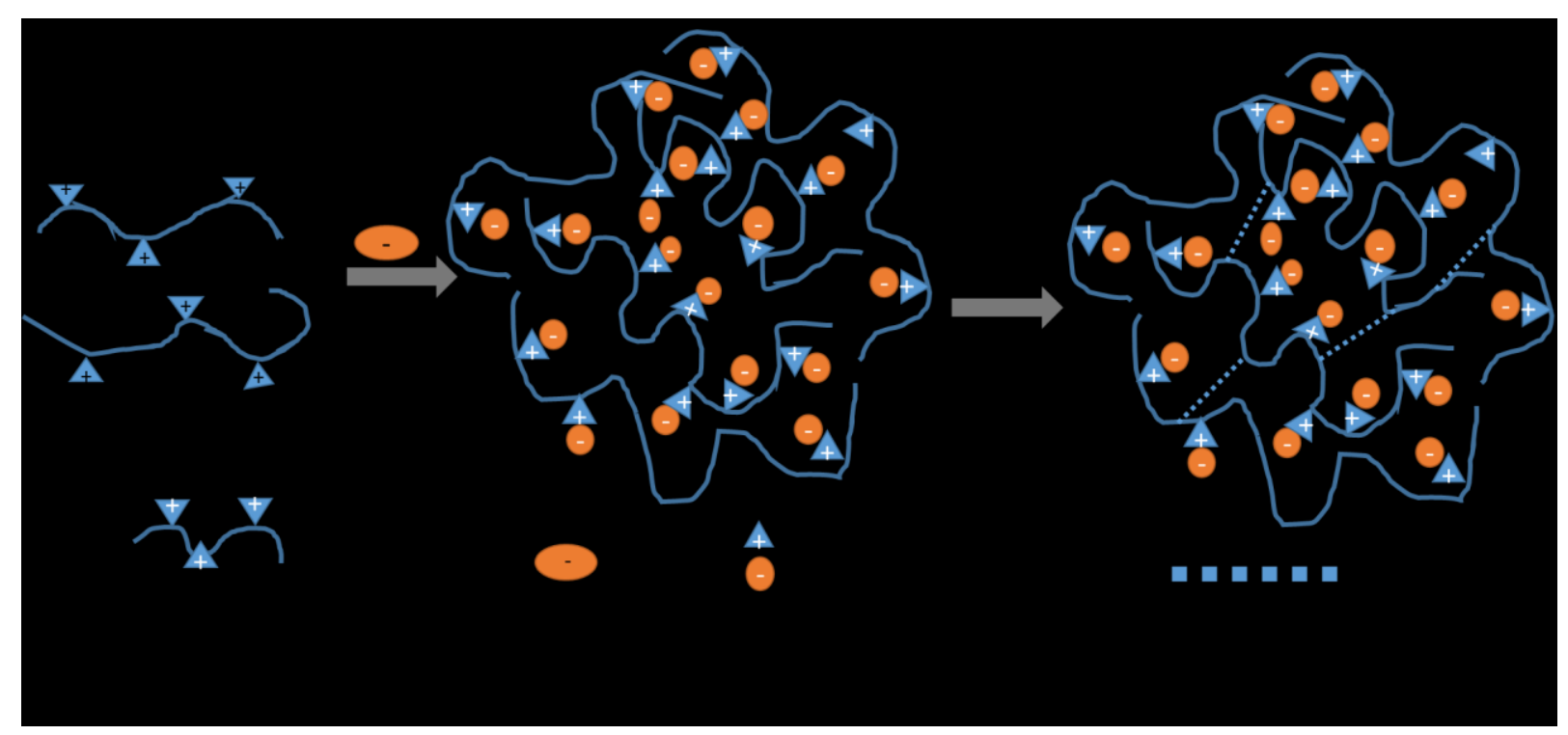

Figure 5: Schematic diagram showing gelation process of chitosan/ß-glycerophosphate mixture at $37^{\circ} \mathrm{C}$

Therapeutic agents have been delivered locally and systemically using thermoresponsive chitosan- $\beta$ GP in situ gelling system (Abdel-Bar et al., 2014; Aliaghaie et al., 2012; Khodaverdi et al., 2012; S. Kim et al., 2010; Peng et al., 2013). However, drug delivery application of chitosan-ß-GP systems has been limited because of poor drug loading, cellular uptake, rapid drug release and short-lived activity of loaded drugs. (Park et al., 2012; Ruel-Gariépy and Leroux, 2004). Thus they have not been used for IDD.

Magnetic delivery system was studied for the adjuvant treatment of superficial BC. BCG powder and magnetite $\left(\mathrm{Fe}_{3} \mathrm{O}_{4}\right)$ nanoparticles were incorporated into chitosan / $\beta$-GP solution. The nanoparticulate component targeted the carrier to bladder tissues under the influence of magnetic field. The resultant $\mathrm{Fe}_{3} \mathrm{O}_{4}$-BCG-chitosan / $\beta$-GP system formed gel in situ and resisted urine wash-off (Zhang et al., 2013). BCG loaded magnetic gel dosage form stimulated greater Th1 immune reaction with increased expression of interleukin-2 (IL-2, $149.3 \pm 8.06 \mathrm{pg} / \mathrm{mL}$ ) and interferon $\gamma($ IFN- $\gamma, 373.47$ $\pm 40.53 \mathrm{pg} / \mathrm{mL}$ ) in the urine and superior antitumor activity (tumor volume of $0.53 \pm 0.27 \mathrm{~mm}^{3}$ ) compared to conventional BCG solution with "1L-2" of $98.84 \pm 7.03 \mathrm{pg} / \mathrm{mL}$; IFN- $\gamma$ of $220.28 \pm 54.19$ $\mathrm{pg} / \mathrm{mL}$ and tumor volume of $1.82 \pm 0.48 \mathrm{~mm}^{3}$. The duration of BCG residence within the bladder tissues was also extended beyond one month, evident by the CD4+ lymphocyte levels detected in submucosal regions: $3913 \pm 467$ lymphocytes were recorded for magnetic BCG nanoparticlehydrogel carrier compared to $2578 \pm 269$ lymphocytes when BCG solution was used.

Chitosan has an intrinsic mucoadhesive property and may be responsible for improved antitumor immune reaction exhibited by the magnetic carrier in the bladder (Zhang et al., 2013). Also, tight 
junctions of the urothelial membrane are loosened up due to their interaction with chitosan, thereby increasing and sustaining local drug concentration (Rosenthal et al., 2012). In vitro release studies were not carried out due to the lack of reliable techniques used for detection and quantification of BCG. Moreover, the BCG radiolabelling technique explored by Shen et al was not helpful (Shen et al., 2007). So, initial burst release profile was suggested based on persistent cytokine expression in rat urine up to 48 hours during in vivo studies. The burst release profile of BCG may result in adverse reactions. So, further studies should be carried out to ascertain if the delivery system is appropriate for BCG or alternative method of BCG quantification may be helpful for dosage determination.

Deguelin has been employed for chemotherapy of lung, breast and colon cancer due to its antiangiogenic potential (Lee et al., 2005; Oh et al., 2007; Peng et al., 2007). However, its clinical use is limited because of its hydrophobicity as well as potential side effects associated with high drug dose (Lee et al., 2005). N-[1-(2, 3-Dioleoyloxy) propyl]-N, N, N-trimethylammonium chloride (DOTAP) has cationic hydrophilic head and hydrophobic chain and nanoparticles formulated using this amphiphilic material are able to solubilise lipophilic drugs and enhance urothelial uptake so that the dose required for the therapy is reduced, minimising toxicity effects. This justifies their acceptance by FDA for the gene-based treatment of lung cancer (Díez et al., 2009; Gopalan et al., 2004; Simberg et al., 2004).

Men et al reported the improved deguelin's aqueous solubility and residence time in the bladder using the formulations composed of amphiphilic DOTAP and monomethoxyl poly(ethylene glycol)poly(E-caprolactone (MPEG-PCL) [DMP] based nanoparticles and thermosensitive in situ gelling Pluronic F127 (F127) (Men et al., 2012). F127 hydrogel improved urothelial uptake and tissue absorption of deguelin while cationic DOTAP/MPEG-PCL nanoparticulate component facilitated sustained drug release (Kabanov et al., 2002). Deguelin loaded nanoparticles had encapsulation efficiency of $98.2 \%$ but rate of loading drug into these nanoparticles was low (4.9\%). In vitro drug release studies were performed using dialysis membrane maintained in a water-bath containing PBS $(\mathrm{pH} 7.4)$ and $0.5 \% \mathrm{w} / \mathrm{w}$ Tween 80 . This formulation formed gel readily at $25^{\circ} \mathrm{C}$ in vitro and fluorescent gel was observed in mice within 10 minutes of intravesical administration which sustained for $2 \mathrm{~h}$ (Men et al., 2012). In vitro cellular uptake studies using DOTAP modified in situ gelling formulation and unmodified nanoparticles loaded with fluorescent coumarin-6 (with similar hydrophobic nature to deguelin) showed that the former was readily taken up by T24 BC cells than the unmodified nanoparticles. In vivo studies using mice confirmed cellular uptake of fluorescent model drug loaded formulation based on fluorescence observed within sections of bladder tissues. The tolerability of deguelin was improved with the intravesical administration of the novel drug 
loaded formulation because similar drug amount $\left(2 \mathrm{mg} \mathrm{kg}^{-1}\right)$ given intravenously to mice, killed them. Thus, D/DMP-F may be safer, effective without causing urethral blockage due to its gradual elimination from the bladder (Men et al., 2012).

Șenyiğit et al have employed chitosan-thioglycolic acid conjugate (CH-TGA) to prepare nanoparticles (CH-TGA NPs) and incorporated them into $2 \%$ chitosan gel (CH-TGA NPs/CH) or in situ gel forming poloxamer (CH-TGA NPs / Plx gel) for improved intravesical delivery of gemcitabine hydrochloride (Gem-HCl) (Senyigiti et al., 2015). Gem-HCl nanoparticles had greater drug loading than DMP nanoparticles evaluated by Men et al (Men et al., 2012) (9.4\% vs $4.9 \%$ ) but the latter had greater encapsulation efficiency than the former (98.2\% vs $19.2 \%)$. This finding may be associated with the differences in the physicochemical properties of the formulation. $\mathrm{CH}-\mathrm{TGA}$ NPs/CH gel was more resistant to dilution by artificial urine (Tyrode solution) than CH-TGA NPs / Plx gel at $37^{\circ} \mathrm{C}$ based on rheological frequency sweep data (Storage modulus $15 \mathrm{~Pa}$ vs $6 \mathrm{~Pa}$ ). In vitro $\mathrm{Gem}-\mathrm{HCl}$ release studies also suggested that the rate of drug release following dispersal of nanoparticles into $\mathrm{CH}$-gel and $\mathrm{Plx}$ gel decreased by a magnitude of 1.5 and 2.6 , respectively as well as release rate of $33.4 \pm 5.0 \%$ vs $19.6 \pm 1.6 \%$ in 4 hours (Senyigiti et al., 2015). During bioadhesion test using bovine bladder mucosa, CH-TGA NPs/CH gel also had improved bioadhesive properties (in terms of its force of detachment from the bladder tissues) compared to Plx gel based carrier $(1.003 \pm 0.048 \mathrm{~N} \cdot \mathrm{mm}$ vs $0.378 \pm 0.022$ $\mathrm{N} \cdot \mathrm{mm}$ ). The incorporation of the drug carriers with Tyrode solution resulted in a $51 \%$ and $80 \%$ reduction in bioadhesive properties, respectively (Senyigiti et al., 2015). Greater percentage of the drug permeated the bladder mucosa for the $\mathrm{CH}$-gel based carrier compared to Plx-gel (33.16 $\pm 5.11 \%$ vs $18.78 \pm 1.97 \%$ ) during ex vivo studies. Thus $\mathrm{CH}-\mathrm{TGA} \mathrm{NPs} / \mathrm{CH}$ gel may be a potential intravesical delivery system for $\mathrm{Gem}-\mathrm{HCl}$ in order to improve efficacy and drug residence time within the bladder. This investigation was intended to mimic the behaviour of the proposed formulation within the urine containing bladder environment. However, the gelation time reported for Plx gel-Tyrode solution and $\mathrm{CH}-\mathrm{TGA}$ NPs/Plx gel - Tyrode solution ( $457 \pm 4$ seconds vs $483 \pm 2$ seconds) at $37^{\circ} \mathrm{C}$ was quite unexpectedly low for formulations with gelation temperature of $51.7 \pm 1.0^{\circ} \mathrm{C}$ and $53.7 \pm 1.9^{\circ} \mathrm{C}$, respectively.

\subsubsection{Liposomal systems}

Liposomes were not usually explored for intravesical drug delivery because of their instability in human urine. Recently, Nakamura's group modified cationic liposomal surfaces with cholesteryl-PEG to overcome their urine aggregation and promote uptake into urothelial tissues (Nakamura et al., 2017). N-(carbonyl-methoxypolyethyleneglycol 200)-1,2-distearoyl-sn-glycero-3-

phosphoethanolamine-PEG (DSPE-PEG) based formulations were the most resistant to aggregation in the presence of human urine relative to 1,2-distearoyl-sn-glycerol, methoxy-PEG 2000 (DSG-PEG) 
and cholesterol-PEG (Chol-PEG). This finding was due to the superior flexible conformation of DSPEPEG in comparison to DSG-PEG and Chol-PEG. Also, the rich density of negative charge on DSPE-PEG shields the cationic liposomes thereby enhancing stability in the urine. Additionally, fluorescently labelled liposomal suspension in human urine was incorporated into MB49 cells and these cells were evaluated using flow cytometry. The surface functionalisation of the cationic liposomes with PEG ensures that the drug carrier is taken up into MB49 murine cells uniformly. Surprisingly, 2 or 5 mol\% Chol-PEG functionalized Cat-LPs were taken up into the cells more efficiently compared to unmodified and other PEG modified liposomes. This result was in contrast to their stability behaviour in human urine as more rigid conformation of Chol-PEG based carrier supported their uptake into MB49 cells (Nakamura et al., 2017). Thus lipid based carriers incorporating both DSPE and Chol-PEG may be formulated for improved stability in human urine as well as cellular uptake into cancerous urothelial tissues.

GuhaSarkar et al explored paclitaxel loaded composite liposomes in gellan hydrogel (PTX-LP-Gel) for intravesical delivery. Paclitaxel was encapsulated efficiently into the drug carrier $(91.2 \pm 0.7 \%)$ because of the affinity of the hydrophobic drug towards lipid bilayers. Apart from being mucoadhesive, gellan is a temperature- and ion-responsive polysaccharide, so it becomes physically cross-linked in the presence of urine, resulting in prolonged retention of the drug carrier onto the urothelial surface. $0.1 \%$ gellan was identified as the optimum concentration for syringeability through the catheter. The liposomal component (124 nm, PDI 0.22, surface charge - $16.8 \mathrm{mV}$ ) enhances urothelial cell permeation as a result of merging with the lipid content of the cell membranes. Based on cryo-TEM results, the size of the drug loaded liposome was increased with paclitaxel encapsulation to $\sim 200 \mathrm{~nm}$. PTX-LP-Gel exhibited a sustained drug release profile over $50 \mathrm{~h}$ $(17.8 \pm 3.0 \%$ of loaded drug) due to the smart matrix of the hydrogel; though porous structure facilitates controlled drug and / or liposome diffusion out of the hydrogel. Cellular uptake studies using CLSM confirmed superior NBT-II and T24 cell internalization of loaded rhodamine-6G, relative to the control cell group. Also, cytotoxic testing of the novel drug carrier using NBT-II and T24 cell lines suggested that they retained their cytotoxic effect with $\mathrm{IC}_{50}$ values of $55.7 \pm 13.0 \mathrm{~nm}$ and $1.9 \pm$ $0.5 \mu \mathrm{m}$, respectively. LP-Gel was not detected in non-target organs during in vivo retention studies and the amount detected in the rat bladder 7 days post instillation was remarkably greater than that of the commercial product, Taxol $(1.71 \pm 0.86 \mu \mathrm{g} / \mathrm{g}$ vs. $0.02 \pm 0.01 \mu \mathrm{g} / \mathrm{g})$. The safety of LP-gel was confirmed based on scanning electron and atomic force microscopic images depicting intact urothelium, with residence of the gel formulation for up to $24 \mathrm{~h}$. This work revealed that the limited mucoadhesiveness associated with conventional liposomes can be overcome by incorporation of liposomes within gellan gel. Moreover, toxic effect of cross-linkers (such as glutaraldehyde and 1- 
ethyl-3-(3-dimethylaminopropyl) carbodiimide hydrochloride) used with mucoadhesive polymers, to improve mucoadhesiveness of liposomes, will be avoided (GuhaSarkar et al., 2017). Overall, this work generated safe, injectable, mucoadhesive, ion-triggered in situ gelling carrier, resistant to $\mathrm{pH}$ changes in the bladder with a sustained release profile.

\subsection{In vitro - in vivo models to study intravesical drug delivery}

Various in vitro and in vivo models have been used to study drug delivery systems intended for intravesical administration. Different types of BC cells have been employed for cell viability studies. Murine sources include MBT-2 (Tamura et al., 2015), MB49 (Nakamura et al., 2017) and NBT-II (GuhaSarkar et al., 2017), while T-24, RT-4, UM-UC-3, 5637 and HT-1376 are human cell lines (GuhaSarkar et al., 2017; Guo et al., 2016; Lu et al., 2015; Martin et al., 2014; Men et al., 2012; Neutsch et al., 2013; Zhang et al., 2014). They differ in terms of their invasive and metastatic tendencies. SV-HUC-1 are healthy bladder cell lines studied to evaluate the biocompatibility of drug carriers (Neutsch et al., 2013). These cells are often maintained in appropriate medium containing $5 \%$ carbon dioxide at $37^{\circ} \mathrm{C}$ for optimal growth (Lu et al., 2015; Martin et al., 2014, 2013; Men et al., 2012; Neutsch et al., 2013; Tamura et al., 2015; Zhang et al., 2014).

During in vitro studies, cell viability in the presence of potential drug carriers was evaluated using different methods, such as bromodeoxyuridine and XTT assay (Neutsch et al., 2013), lactate dehydrogenase assay (Tamura et al., 2015), MTT assay (Guo et al., 2016; Lu et al., 2015; Men et al., 2012; Zhang et al., 2014) and sulphorhodamine-B colorimetry (GuhaSarkar et al., 2017). The damage of the intravesical carriers to cell membrane was measured in terms of specific enzymes or antibodies release into the cytosol when carriers were mixed with malignant cells. Some researchers did not carry out in vitro cell viability or cytotoxicity testing of their formulations (Cook et al., 2015; Lin et al., 2014; Senyigiti et al.,2015). However, in vitro drug release (Cook et al., 2015; Senyigiti et al., 2015) and floating tendency (Lin et al., 2014) studies of their formulation in the presence of artificial urine were evaluated.

There are detailed protocols available for the preparation of artificial urine for in vitro cell based studies, which is representative of the components of human urine but they are varied in composition and concentration of their constituents, which imparts on their $\mathrm{pH}$ (6.5-7.8), specific gravity (1.008-1.02 g/mL) and osmolality value (430-861 mOsm/kg) (Brooks and Keevil, 1997; Brown et al., 1989; Christmas et al., 2002; Chutipongtanate and Thongboonkerd, 2010; Grases and Llobera, 1998; Mayrovitz and Sims, 2001; Opalko et al., 1997). Examples of constituents include urea, uric acid, creatinine, trisodium citrate, sodium chloride, potassium chloride, ammonium chloride, calcium chloride dehydrate, magnesium sulphate heptahydrate, sodium bicarbonate, disodium oxalate, 
sodium sulphate, sodium dihydrogen phosphate and disodium hydrogen phosphate (Brooks and Keevil, 1997; Brown et al., 1989; Christmas et al., 2002; Grases and Llobera, 1998; Mayrovitz and Sims, 2001; Opalko et al., 1997). The artificial urine with $\mathrm{pH}$, specific gravity and osmolality of 6.2, $1.01 \mathrm{~g} / \mathrm{mL}$ and $446 \mathrm{mOsm} / \mathrm{kg}$, respectively, was appropriate for various biomedical applications (Chutipongtanate and Thongboonkerd, 2010).

Martin et al evaluated the uptake of fluorescent carriers suspended in artificial urine into healthy human ureter using ex vivo binding assay (Martin et al., 2013). The in vitro cytotoxicity of free drug, blank nanoparticles, drug loaded modified and unmodified PLGA nanoparticles, on T-24 cells (metastatic, invasive high grade BC), RT-4 cells (papillary, well differentiated, non-invasive) and UMUC-3 cells (highly metastatic) were studied using WST-1 reagent and IC $\mathrm{C}_{50}$ values determined (Martin et al., 2013). These values may help to establish the dose of formulation that would be toxic to urothelial cells.

During in vivo studies, mice were induced with human bladder cancer (orthotopic model) by transurethral implantation (Tamura et al., 2015) or subcutaneous injection (Martin et al., 2014,

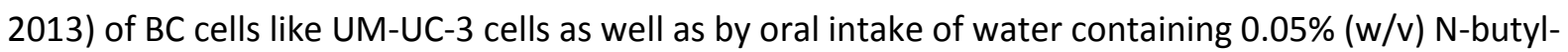
$\mathrm{N}$-(4-hydroxybutyl)-nitrosamine for 20 weeks (Guo et al., 2016). Predetermined concentration of carriers were instilled and the degree of tumor regression determined from the weight of bladder tumor after sacrificing mice (Martin et al., 2014, 2013; Tamura et al., 2015). The actual drug taken up may be evaluated based on LC-MS/MS analysis of extracts from bladder tumor homogenate (Tamura et al., 2015). Other authors quantified in vivo retention of drug carriers in terms of observable fluorescence using fluorescence microscopy (Lu et al., 2015; Martin et al., 2014; Neutsch et al., 2013) or acid-fast staining and / or HE staining (Zhang et al., 2013). Men et al (Men et al., 2012) also used mice but did not test the antitumor efficacy by induction of bladder cancer. They simply tested the drug uptake into bladder tissues from the delivery system as well as its resistance to urine wash-out. Nevertheless, they evaluated the cytotoxic effects of free deguelin, drug nanoparticles and drug loaded hydrogel-nanoparticle composite formulations on T-24 cells while the anti-angiogenic potential of deguelin was assessed using transgenic zebrafish model (Men et al., 2012).

Similar number (six) of injections were administered to mice and rats based malignant models but dose and dosing interval of the drug carriers differ probably due to pharmacological profile of various chemotherapeutic agents used (Martin et al., 2013; Tamura et al., 2015; Zhang et al., 2013). Therefore, it would be difficult to compare degree of tumor regression across studies. Moreover, some studies were less detailed in terms of the original volume of tumor (Tamura et al., 2015). Thus it is not easy to ascertain the degree of tumor regression by the final volume of tumor observed. 
Wistar rats are typically used for in vivo studies, so Lin et al used these rats to assess the urine washoff resistance and sustained release profile of Poloxamer-based floating and non-floating carriers (Lin et al., 2014). Zhang et al (Zhang et al., 2013) used similar rats to evaluate urothelial cellular uptake of chitosan/ $\mathrm{B}-\mathrm{GP} / \mathrm{Fe}_{3} \mathrm{O}_{4}$-magnetic hydrogel-nanoparticles system. The immunological response of rat bladder to the intravesical instillation of BCG-based carriers was quantified by urinary analysis of cytokines and tissue histochemical analysis of CD4+ T cells (Zhang et al., 2013). GuhaSarkar's group evaluated the in vivo retention of rhodamine and paclitaxel loaded liposomes and liposome-gel systems using healthy female and male rats (GuhaSarkar et al., 2017). However, the antitumor effect of the drug loaded formulations was not investigated in rats, in addition to their retention in the bladder.

On the other hand, in vivo testing of formulations was not carried out in some studies reported (Cook et al., 2015; Lu et al., 2015; Neutsch et al., 2013; Senyigiti et al., 2015; Zhang et al., 2014). However, ex vivo mucoadhesive studies of some formulations were conducted using porcine (Cook et al., 2015; Lu et al., 2015; Zhang et al., 2014) or bovine (Senyigiti et al., 2015) bladder tissues. However, they quantified the mucoadhesiveness of their drug carriers differently using confocal laser-scanning microscope(Lu et al., 2015; Zhang et al., 2014), fluorescence stereomicroscope (Cook et al., 2015) and TA-XT Plus texture analyser (Senyigiti et al., 2015).

\subsection{Clinical trials}

TCGel $^{\circledR}$, a polymeric thermoresponsive hydrogel containing Pluronic F-127 (27\%), PEG-400 (1.1\%), HPMC (0.3\%), double distilled water (71.6\%) was developed by TheraCoat Ltd (Israel). It exhibited improved safety and residence within the bladder cavity between 6 to 8 hours and gradually eliminated during urine voiding, in comparison to simple mitomycin $C$ solution during preclinical evaluation (Zacchè et al., 2015). Thus it was assessed for intravesical application by mixing TCGel ${ }^{\circledR}$ with 40mg mitomycin C (standard dose prior to surgery) and pharmacological effect compared with same amount of mitomycin $\mathrm{C}$ mixed with water, in an ongoing trial for management of low risk recurrent NMIBC (TheraCoat Ltd., 2015).

\section{Conclusion}

The intravesical route is the most viable means of improving drug delivery for bladder cancer treatment, especially at the early stages, due to the limitations of oral and systemic routes. However, intravesical drug delivery has disadvantages, like drug dilution by urine and drug wash-out during micturition when conventional formulations made of simple solution of the chemotherapeutic agent are used. Moreover, the urothelium limits permeation of potentially useful 
therapeutic agents for $\mathrm{BC}$ treatment while carrying out its regulatory role. This results in frequent dosing or catheter retention within the urethral tract that leads to bladder irritation and infection.

Drug carriers reviewed are of polymeric nature with potential to treat superficial $\mathrm{BC}$ and prevent disease progression to its metastatic and advanced forms. Moreover, the composite nanoparticulate and in situ gelling formulations are able to combine benefits of both delivery systems to generate dosage forms, with improved safety, efficacy and sustained release profile.

There are variations in the design of the in vitro and in vivo studies as well as evaluation of data generated from such studies. Some studies were not detailed enough to allow for comparison of cytotoxic or mucoadhesive profiles. Also, some authors did not carry out particular in vitro and ex vivo studies conducted by others, making it difficult to establish dosage regimen for such formulations.

The issue of formulation design (modulation of formulation properties to generate uniform thin gel layer in situ, adequate strength and sustained drug release) for higher capacity of human bladder, identified by GuhaSarkar et al (GuhaSarkar and Banerjee, 2010) still persist. This has prevented promising formulations from being tested in human bladder during clinical trials. However, their findings have suggested that solubilisation of drugs in amphiphilic systems; surface modification of particulate systems and incorporation of such particulate systems into in situ gelling formulations would generate advanced carriers with superior drug loading, safety, in situ gelling, mucoadhesive / floating and selective bladder cancer cell penetrating features that would improve the cytotoxic profile of the incorporated therapeutics. Drug carriers that would explore combination of delivery strategies would be desirable in order to prevent $\mathrm{BC}$ recurrence and progression.

Promising safety and cytotoxicity data generated from some of the studies offer hope that single drug loaded carriers may be investigated instead of multiple drugs based delivery systems widely explored in ongoing clinical trials for bladder cancer treatment. The harmonisation of the acceptable and realistic protocols for in vitro and in vivo models for studying intravesical delivery may accelerate the translation of some of the formulations, currently being developed, into the clinic. Therapeutic outcomes of patients would also be improved with promising disease prognosis.

\section{References}

Abdel-Bar, H.M., Abdel-Reheem, A.Y., Osman, R., Awad, G.A.S., Mortada, N., 2014. Defining cisplatin incorporation properties in thermosensitive injectable biodegradable hydrogel for sustained delivery and enhanced cytotoxicity. Int. J. Pharm. 477, 623-630.

Alexandridis and Hatton, 1995. Poly(ethylene oxide)poly(propylene oxide)poly(ethylene oxide) block copolymer surfactants in aqueous solutions and at interfaces: thermodynamics, structure, 
dynamics, and modeling. Colloids Surfaces A Physicochem. Eng. Asp. 96, 1-46.

Aliaghaie, M., Mirzadeh, H., Dashtimoghadam, E., Taranejoo, S., 2012. Investigation of gelation mechanism of an injectable hydrogel based on chitosan by rheological measurements for a drug delivery application. Soft Matter 8, 7128.

Amling, C.L., 2001. Diagnosis and management of superficial bladder cancer. Curr. Probl. Cancer 25, 219-278.

Anthony, T., Fong, P., Goyal, A., Saltzman, W.M., Moss, R.L., Breuer, C., 2005. Development of a parathyroid hormone-controlled release system as a potential surgical treatment for hypoparathyroidism. J. Pediatr. Surg. 40, 81-85.

Apfelthaler, C., Anzengruber, M., Gabor, F., Wirth, M., 2017. Poly - (L) - glutamic acid drug delivery system for the intravesical therapy of bladder cancer using WGA as targeting moiety. Eur. J. Pharm. Biopharm. 115, 131-139. doi:10.1016/j.ejpb.2017.02.016

Aziz, A., Shariat, S.F., Roghmann, F., Brookman-May, S., Stief, C.G., Rink, M., Chun, F.K., Fisch, M., Novotny, V., Froehner, M., Wirth, M.P., Schnabel, M.J., Fritsche, H.M., Burger, M., Pycha, A., Brisuda, A., Babjuk, M., Vallo, S., Haferkamp, A., Roigas, J., Noldus, J., Stredele, R., Volkmer, B., Bastian, P.J., Xylinas, E., May, M., 2016. Prediction of cancer-specific survival after radical cystectomy in pT4a urothelial carcinoma of the bladder: Development of a tool for clinical decision-making. BJU Int. 117, 272-279.

Barocas, D.A., Globe, D.R., Colayco, D.C., Onyenwenyi, A., Bruno, A.S., Bramley, T.J., Spear, R.J., 2012. Surveillance and treatment of non-muscle-invasive bladder cancer in the USA. Adv. Urol. 2012, 19-24.

Barocas et al., 2012. Surveillance and treatment of non-muscle-invasive bladder cancer in the USA. Adv. Urol. 2012, 19-24.

Barthelmes et al., 2012. Thiolated particles as effective intravesical drug delivery systems for treatment of bladder related diseases. Nanomedicine 8, 65 .

Barthelmes et al., 2011a. Development of a mucoadhesive nanoparticulate drug delivery system for a targeted drug release in the bladder. Int. J. Pharm. 416, 339-345.

Barthelmes et al., 2011b. Thiomer nanoparticles: stabilization via covalent cross-linking. Drug Deliv $18,613-619$.

Bernkop-Schnürch, A., Greimel, A., 2005. Thiomers: The next generation of mucoadhesive polymers. Am. J. Drug Deliv. 3, 141-154.

Bies, C., Lehr, C.-M., Woodley, J.F., 2004. Lectin-mediated drug targeting: history and applications. Adv. Drug Deliv. Rev. 56, 425-435.

Bischoff, C.J., Clark, P.E., 2009. Bladder cancer. Curr.Opin.Oncol. 21, 272-277.

Bogataj, M., Mrhar, A., Korošec, L., 1999. Influence of physicochemical and biological parameters on drug release from microspheres adhered on vesical and intestinal mucosa. Int. J. Pharm. 177, 211-220.

Bonengel, S., Bernkop-Schnürch, A., 2014. Thiomers--from bench to market. J. Control. Release 195, 120-9.

Brannigan, R.P., Khutoryanskiy, V. V., 2017. Synthesis and evaluation of mucoadhesive acryloylquaternized PDMAEMA nanogels for ocular drug delivery. Colloids Surfaces B Biointerfaces 155, 538-543. doi:10.1016/j.colsurfb.2017.04.050

Brooks, T., Keevil, C.W., 1997. A simple artificial urine for the growth of urinary pathogens. Lett. 
Appl. Microbiol. 24, 203-206.

Brown, P., Ackermann, D., Finlayson, B., 1989. Calcium oxalate dihydrate (weddellite) precipitation. J. Cryst. Growth 98, 285-292.

Buckley, M.T., Yoon, J., Yee, H., Chiriboga, L., Liebes, L., Ara, G., Qian, X., Bajorin, D.F., Sun, T.-T., Wu, X.-R., Osman, I., 2007. The histone deacetylase inhibitor belinostat (PXD101) suppresses bladder cancer cell growth in vitro and in vivo. J. Transl. Med. 5, 49.

Burnier, A., Shimizu, Y., Dai, Y., Nakashima, M., Matsui, Y., Ogawa, O., Rosser, C.J., Furuya, H., 2015. CXCL1 is elevated in the urine of bladder cancer patients. Springerplus 4, 610.

Cancer Research, U.K., 2017. Cancer Registration Statistics, England: 2015 [WWW Document]. Stat. Bull. URL https://www.ons.gov.uk/peoplepopulationandcommunity/healthandsocialcare/conditionsand diseases/bulletins/cancerregistrationstatisticsengland/2014 (accessed 8.10.16).

Cancer Research UK, 2016. Bladder cancer mortality statistics: Projections of mortality for bladder cancer [WWW Document]. Cancer Stat. Newsl.

Cardillo, M.R., Castagna, G., Memeo, L., De Bernardinis, E., Di Silverio, F., 2000. Epidermal growth factor receptor, MUC-1 and MUC-2 in bladder cancer. J Exp Clin Cancer Res 19, 225-233.

Chen et al., 2015, 2015. Review: Application of Nanoparticles in Urothelial Cancer of the Urinary Bladder. J. Med. Biol. Eng. 35, 419-427.

Cheng, C.J., Saltzman, W.M., 2011. Enhanced siRNA delivery into cells by exploiting the synergy between targeting ligands and cell-penetrating peptides. Biomaterials 32, 6194-6203.

Cheung, G., Sahai, A., Billia, M., Dasgupta, P., Khan, M.S., 2013. Recent advances in the diagnosis and treatment of bladder cancer 1-8.

Choi, H.G., Oh, Y.K., Kim, C.K., 1998. In situ gelling and mucoadhesive liquid suppository containing acetaminophen: Enhanced bioavailability. Int. J. Pharm. 165, 23-32.

Christmas, K.G., Gower, L.B., Khan, S.R., El-Shall, H., 2002. Aggregation and Dispersion Characteristics of Calcium Oxalate Monohydrate: Effect of Urinary Species. J. Colloid Interface Sci. 256, 168174.

Chutipongtanate, S., Thongboonkerd, V., 2010. Systematic comparisons of artificial urine formulas for in vitro cellular study. Anal. Biochem. 402, 110-2.

Cook, M.T., Schmidt, S.A., Lee, E., Samprasit, W., Opanasopit, P., Khutoryanskiy, V. V., 2015. Synthesis of mucoadhesive thiol-bearing microgels from 2-(acetylthio)ethylacrylate and 2hydroxyethylmethacrylate: novel drug delivery systems for chemotherapeutic agents to the bladder. J. Mater. Chem. B 3, 6599-6604.

Cu, Y., Booth, C.J., Saltzman, W.M., 2011. In vivo distribution of surface-modified PLGA nanoparticles following intravaginal delivery. J. Control. Release 156, 258-264.

Dalbagni, G., 2007. The management of superficial bladder cancer. Nat. Clin. Pract. Urol. 4, 254-60.

Davidovich-Pinhas, M., Bianco-Peled, H., 2011. Alginate-PEGAc: A new mucoadhesive polymer. Acta Biomater. 7, 625-633.

Dhakal, B.K., Kulesus, R.R., Mulvey, M. a, 2008. Mechanisms and consequences of bladder cell invasion by uropathogenic Escherichia coli. Eur. J. Clin. Invest. 38 Suppl 2, 2-11.

Díez, S., Navarro, G., de ILarduya, C.T., 2009. In vivo targeted gene delivery by cationic nanoparticles for treatment of hepatocellular carcinoma. J. Gene Med. 11, 38-45. 
Eble et al., 2004, 2004. Pathology and Genetics of Tumours of the Urinary System and Male Genital Organs. BJU Int 94, 675.

Elstad, N.L., Fowers, K.D., 2009. OncoGel (ReGel/paclitaxel)--clinical applications for a novel paclitaxel delivery system. Adv. Drug Deliv. Rev. 61, 785-94.

Eto H., Oka Y., Ueno K., Nakamura I, Yoshimura K., Arakawa S., Kamidono S., Obe S., Ogawa T., H.G., 1994. Comparison of the prophylactic usefulness of epirubicin and doxorubicin in the treatment of superficial bladder cancer by intravesical instillation: A multicenter randomized trial. Cancer Chemother. Pharmacol. 35, S46-S51.

Fahmy, T.M., Samstein, R.M., Harness, C.C., Saltzman, W.M., 2005. Surface modification of biodegradable polyesters with fatty acid conjugates for improved drug targeting. Biomaterials 26, 5727-5736.

Giannantoni, A., Di Stasi, S.M., Chancellor, M.B., Costantini, E., Porena, M., 2006. New Frontiers in Intravesical Therapies and Drug Delivery. Eur. Urol.

Goda, T., Goto, Y., Ishihara, K., 2010. Cell-penetrating macromolecules: Direct penetration of amphipathic phospholipid polymers across plasma membrane of living cells. Biomaterials 31 , 2380-2387.

Gong, C., Qi, T., Wei, X., Qu, Y., Wu, Q., Luo, F., Qian, Z., 2012. Thermosensitive Polymeric Hydrogels As Drug Delivery Systems. Curr. Med. Chem. 20, 79-94.

Gopalan, B., Ito, I., Branch, C.D., Stephens, C., Roth, J. a, Ramesh, R., 2004. Nanoparticle based systemic gene therapy for lung cancer: molecular mechanisms and strategies to suppress nanoparticle-mediated inflammatory response. Technol. Cancer Res. Treat. 3, 647-57.

Grabnar, I., Bogataj, M., Beli , A., Logar, V., Karba, R., Mrhar, A., 2006. Kinetic model of drug distribution in the urinary bladder wall following intravesical instillation 322, 52-59.

Grases, F., Llobera, A., 1998. Experimental model to study sedimentary kidney stones. Micron 29, 105-111.

Gray, M., 2012. Traces: Making sense of urodynamics testing - Part 9: Evaluation of detrusor response to bladder filling. Urol. Nurs. 32, 21-28, 18.

GuhaSarkar, S., Banerjee, R., 2010. Intravesical drug delivery: Challenges, current status, opportunities and novel strategies. J. Control. Release 148, 147-159.

GuhaSarkar, S., More, P., Banerjee, R., 2017. Urothelium-adherent, ion-triggered liposome-in-gel system as a platform for intravesical drug delivery. J. Control. Release 245, 147-156. doi:10.1016/j.jconrel.2016.11.031

Guo, H., Xu, W., Chen, J., Yan, L., Ding, J., Hou, Y., Chen, X., 2016. Positively charged polypeptide nanogel enhances mucoadhesion and penetrability of 10-hydroxycamptothecin in orthotopic bladder carcinoma. J. Control. Release. doi:10.1016/j.jconrel.2016.12.041

Haltner, E., Easson, J.H., Lehr, C.M., 1997. Lectins and bacterial invasion factors for controlling endoand transcytosis of bioadhesive drug carrier systems. Eur. J. Pharm. Biopharm. 44, 3-13.

He, C., Hu, Y., Yin, L., Tang, C., Yin, C., 2010. Effects of particle size and surface charge on cellular uptake and biodistribution of polymeric nanoparticles. Biomaterials 31, 3657-3666.

He, C., Kim, S.W., Lee, D.S., 2008. In situ gelling stimuli-sensitive block copolymer hydrogels for drug delivery. J. Control. Release 127, 189-207.

Hennig, A., Gabriel, G.J., Tew, G.N., Matile, S., 2008. Stimuli-responsive polyguanidinooxanorbornene membrane transporters as multicomponent sensors in complex matrices. J. 
Am. Chem. Soc. 130, 10338-10344.

Irmukhametova, G.S., Mun, G. a., Khutoryanskiy, V. V., 2011. Thiolated mucoadhesive and PEGylated nonmucoadhesive organosilica nanoparticles from 3-mercaptopropyltrimethoxysilane. Langmuir 27, 9551-9556.

Kabanov, A. V., Lemieux, P., Vinogradov, S., Alakhov, V., 2002. Pluronic block copolymers: Novel functional molecules for gene therapy. Adv. Drug Deliv. Rev. 54, 223-233.

Kątnik-Prastowska, I., Lis, J., Matejuk, A., 2014. Glycosylation of uroplakins. Implications for bladder physiopathology. Glycoconj. J. 31, 623-36.

Kaufman, D.S., 2006. Challenges in the treatment of bladder cancer. Ann. Oncol. 17 Suppl 5, v106-12.

Kaufman, D.S., Shipley, W.U., Feldman, A.S., 2009. Bladder cancer. Lancet 374, 239-249.

Khan, A., Benboubetra, M., Sayyed, P.Z., Ng, K.W., Fox, S., Beck, G., Benter, I.F., Akhtar, S., 2004. Sustained polymeric delivery of gene silencing antisense ODNs, siRNA, DNAzymes and ribozymes: in vitro and in vivo studies. J. Drug Target. 12, 393-404.

Khandelwal, P., Abraham, S.N., Apodaca, G., 2009. Cell biology and physiology of the uroepithelium. Am. J. Physiol. Renal Physiol. 297, F1477-501.

Khetan, S., Guvendiren, M., Legant, W.R., Cohen, D.M., Chen, C.S., Burdick, J. a, 2013. Degradationmediated cellular traction directs stem cell fate in covalently crosslinked three-dimensional hydrogels. Nat. Mater. 12, 458-65.

Khodaverdi, E., Tafaghodi, M., Ganji, F., Abnoos, K., Naghizadeh, H., 2012. In vitro insulin release from thermosensitive chitosan hydrogel. AAPS PharmSciTech 13, 460-6.

Khutoryanskiy, V. V., 2011. Advances in Mucoadhesion and Mucoadhesive Polymers. Macromol. Biosci. 11, 748-764.

Kikuchi, E., Menendez, S., Ozu, C., Ohori, M., Cordon-cardo, C., Logg, C.R., Kasahara, N., Bochner, B.H., 2007. Highly Efficient Gene Delivery for Bladder Cancers by Intravesically Administered Replication-Competent Retroviral Vectors Cancer Therapy : Preclinical Highly Efficient Gene Delivery for Bladder Cancers by Intravesically Administered Replication-Competent. Clin. Cancer Res. 13, 4511-4519.

Kim, B., Han, G., Toley, B.J., Kim, C.-K., Rotello, V.M., Forbes, N.S., 2010. Tuning payload delivery in tumour cylindroids using gold nanoparticles. Nat. Nanotechnol. 5, 465-472.

Kim, M.R., Park, T.G., 2002. Temperature-responsive and degradable hyaluronic acid/Pluronic composite hydrogels for controlled release of human growth hormone. J. Control. Release 80, 69-77.

Kim, S., Nishimoto, S.K., Bumgardner, J.D., Haggard, W.O., Gaber, M.W., Yang, Y., 2010. Chitosan/bglycerophosphate Thermo-Sensitive gel for the Delivery of Ellagic Acid for the Treatment of Brain Cancer. Biomaterials 31, 4157.

Knemeyer, I., Wientjes, M.G., Au, J.L., 1999. Cremophor reduces paclitaxel penetration into bladder wall during intravesical treatment. Cancer Chemother. Pharmacol. 44, 241-8.

Konety, B.R., Joyce, G.F., Wise, M., 2007. Bladder and upper tract urothelial cancer. J. Urol. 177, 1636-45.

Kong, X.-T., Deng, F.-M., Hu, P., Liang, F.-X., Zhou, G., Auerbach, A.B., Genieser, N., Nelson, P.K., Robbins, E.S., Shapiro, E., Kachar, B., Sun, T.-T., 2004. Roles of uroplakins in plaque formation, umbrella cell enlargement, and urinary tract diseases. J. Cell Biol. 167, 1195-204. 
Kopeček, J., 2007. Hydrogel biomaterials: A smart future? Biomaterials 28, 5185-5192.

Lamm, D.L., McGee, W.R., Hale, K., 2005. Bladder cancer: current optimal intravesical treatment. Urol. Nurs. 25, 323-6, 331-2.

Lavertu, M., Filion, D., Buschmann, M.D., 2008. Heat-induced transfer of protons from chitosan to glycerol phosphate produces chitosan precipitation and gelation. Biomacromolecules 9, 640650.

Le Visage, C., Rioux-Leclercq, N., Haller, M., Breton, P., Malavaud, B., Leong, K., 2004. Efficacy of paclitaxel released from bio-adhesive polymer microspheres on model superficial bladder cancer. J. Urol. 171, 1324-9.

Lee, H.Y., Oh, S.H., Woo, J.K., Kim, W.Y., Van Pelt, C.S., Price, R.E., Cody, D., Tran, H., Pezzuto, J.M., Moriarty, R.M., Hong, W.K., 2005. Chemopreventive effects of deguelin, a novel Akt inhibitor, on tobacco-induced lung tumorigenesis. J. Natl. Cancer Inst. 97, 1695-1699.

Lerner, S.P., Au, J.L., 2008. Risk-adapted use of intravesical chemotherapy. BJU Int 102, 1247-1253.

Lewis, S.A., 2000. Everything you wanted to know about the bladder epithelium but were afraid to ask. Am. J. Physiol. Renal Physiol. 278, F867-74.

Lin, T., Wu, J., Zhao, X., Lian, H., Yuan, A., Tang, X., Zhao, S., Guo, H., Hu, Y., 2014. In situ floating hydrogel for intravesical delivery of adriamycin without blocking urinary tract. J. Pharm. Sci. 103, 927-936.

Lu, S., Neoh, K.G., Kang, E.T., Mahendran, R., Chiong, E., 2015. Mucoadhesive polyacrylamide nanogel as a potential hydrophobic drug carrier for intravesical bladder cancer therapy. Eur. J. Pharm. Sci. 72, 57-68.

Lu, Z., Yeh, T., Tsai, M., Au, J.L., Wientjes, M.G., 2004a. Paclitaxel-Loaded Gelatin Nanoparticles for Intravesical Bladder Cancer Therapy Paclitaxel-Loaded Gelatin Nanoparticles for Intravesical Bladder Cancer Therapy 10, 7677-7684.

Lu, Z., Yeh, T.K., Tsai, M., Au, J.L.S., Wientjes, M.G., 2004b. Paclitaxel-loaded gelatin nanoparticles for intravesical bladder cancer therapy. Clin. Cancer Res. 10, 7677-7684.

Martin, D.T., Hoimes, C.J., Kaimakliotis, H.Z., Cheng, C.J., Zhang, K., Liu, J., Wheeler, M.A., Kelly, W.K., Tew, G.N., Saltzman, W.M., Weiss, R.M., 2013. Nanoparticles for urothelium penetration and delivery of the histone deacetylase inhibitor belinostat for treatment of bladder cancer. Nanomedicine 9, 1124-34.

Martin, D.T., Steinbach, J.M., Liu, J., Shimizu, S., Kaimakliotis, H.Z., Wheeler, M. a, Hittelman, A.B., Mark Saltzman, W., Weiss, R.M., 2014. Surface-Modified Nanoparticles Enhance Transurothelial Penetration and Delivery of Survivin siRNA in Treating Bladder Cancer. Mol. Cancer Ther. 13, 71-81.

Matsushima, M., Horinaga, M., Fukuyama, R., Yanaihara, H., Kikuchi, E., Kawachi, M., lida, M., Nakahira, Y., Oya, M., Asakura, H., 2011. Enhanced antitumor effect of combination intravesical mitomycin $\mathrm{C}$ and bacillus Calmette-Guerin therapy in an orthotopic bladder cancer model. Oncol. Lett. 2, 13-19.

Mayrovitz, H.N., Sims, N., 2001. Biophysical effects of water and synthetic urine on skin. Adv. Skin Wound Care 14, 302-308.

Men, K., Liu, W., Li, L., Duan, X., Wang, P., Gou, M., Wei, X., Gao, X., Wang, B., Du, Y., Huang, M., Chen, L., Qian, Z., Wei, Y., 2012. Delivering instilled hydrophobic drug to the bladder by a cationic nanoparticle and thermo-sensitive hydrogel composite system. Nanoscale 4, 6425. 
Moch, H., Cubilla, A.L., Humphrey, P.A., Reuter, V.E., Ulbright, T.M., 2016. The 2016 WHO Classification of Tumours of the Urinary System and Male Genital Organs-Part A: Renal, Penile, and Testicular Tumours. Eur. Urol. 1-14.

Mortensen, K., 1993. Structural Study on the Micelle Formation of PEO-PPO-PEO triblock copolymer in aqueous solutions. Macromolecules 26, 805-812.

Mun, E.A., Williams, A.C., Khutoryanskiy, V. V., 2016. Adhesion of thiolated silica nanoparticles to urinary bladder mucosa: Effects of PEGylation, thiol content and particle size. Int. J. Pharm. $512,32-38$.

Nakamura, T., Noma, Y., Sakurai, Y., Harashima, H., 2017. Modifying Cationic Liposomes with Cholesteryl-PEG Prevents Their Aggregation in Human Urine and Enhances Cellular Uptake by Bladder Cancer Cells. Biol. Pharm. Bull. 40, 234-237. doi:10.1248/bpb.b16-00770

Narendra, K.S., Lee, D.S., 20014. In situ gelling pH- temperature-sensitive biodegradable block copolymer hydrogels for drug delivery. J. Control. Release 193, 214-227.

Neutsch, L., Eggenreich, B., Herwig, E., Marchetti-Deschmann, M., Allmaier, G., Gabor, F., Wirth, M., 2012. Lectin bioconjugates trigger urothelial cytoinvasion - A glycotargeted approach for improved intravesical drug delivery. Eur. J. Pharm. Biopharm. 82, 367-375.

Neutsch, L., Plattner, V.E., Polster-Wildhofen, S., Zidar, A., Chott, A., Borchard, G., Zechner, O., Gabor, F., Wirth, M., 2011. Lectin mediated biorecognition as a novel strategy for targeted delivery to bladder cancer. J. Urol. 186, 1481-1488.

Neutsch, L., Wirth, E.-M., Spijker, S., Pichl, C., Kählig, H., Gabor, F., Wirth, M., 2013. Synergistic targeting/prodrug strategies for intravesical drug delivery--lectin-modified PLGA microparticles enhance cytotoxicity of stearoyl gemcitabine by contact-dependent transfer. J. Control. Release $169,62-72$.

Nguyen, M.K., Lee, D.S., 2010. Injectable biodegradable hydrogels. Macromol. Biosci.

NICE, 2015. National Institute for Health and care Excellence guidelines: Bladder cancer diagnosis and management [WWW Document]. URL https://www.nice.org.uk/guidance/ng2/chapter/1Recommendations (accessed 8.11.16).

Niranjan, R., Koushik, C., Saravanan, S., Moorthi, A., Vairamani, M., Selvamurugan, N., 2013. A novel injectable temperature-sensitive zinc doped chitosan/ $\beta$-glycerophosphate hydrogel for bone tissue engineering. Int. J. Biol. Macromol. 54, 24-29.

Oh, S.H., Woo, J.K., Yazici, Y.D., Myers, J.N., Kim, W.Y., Jin, Q., Hong, S.S., Park, H.J., Suh, Y.G., Kim, K.W., Hong, W.K., Lee, H.Y., 2007. Structural basis for depletion of heat shock protein 90 client proteins by deguelin. J. Natl. Cancer Inst. 99, 949-961.

Oommen, O.P., Wang, S., Kisiel, M., Sloff, M., Hilborn, J., Varghese, O.P., 2013. Smart design of stable extracellular matrix mimetic hydrogel: Synthesis, characterization, and in vitro and in vivo evaluation for tissue engineering. Adv. Funct. Mater. 23, 1273-1280.

Opalko, F.J., Adair, J.H., Khan, S.R., 1997. Heterogeneous nucleation of calcium oxalate trihydrate in artificial urine by constant composition. J. Cryst. Growth 181, 410-417.

Park, M.H., Joo, M.K., Choi, B.G., Jeong, B., 2012. Biodegradable thermogels. Acc. Chem. Res. 45, 424-433.

Parkin, J., Shea, C., Sant, G.R., 1997. Intravesical dimethyl sulfoxide (DMSO) for interstitial cystitis--a practical approach. Urology 49, 105-7.

Patois, E., Osorio-Da Cruz, S., Tille, J.C., Walpoth, B., Gurny, R., Jordan, O., 2009. Novel 
thermosensitive chitosan hydrogels: In vivo evaluation. J. Biomed. Mater. Res. - Part A 91, 324330.

Pawar, V.K., Kansal, S., Garg, G., Awasthi, R., Singodia, D., Kulkarni, G.T., 2011. Gastroretentive dosage forms: A review with special emphasis on floating drug delivery systems. Drug Deliv. 18, 97-110.

Peng, X., Karna, P., Regan, R.M.O., Liu, X., Naithani, R., Moriarty, R.M., Wood, W.C., Lee, H., Yang, L., 2007. Down-Regulation of Inhibitor of Apoptosis Proteins by Deguelin Selectively Induces Apoptosis in Breast Cancer Cells. October 71, 101-111.

Peng, Y., Li, J., Li, J., Fei, Y., Dong, J., Pan, W., 2013. Optimization of thermosensitive chitosan hydrogels for the sustained delivery of venlafaxine hydrochloride. Int. J. Pharm. 441, 482-490.

Prajapati, V.D., Jani, G.K., Khutliwala, T. a., Zala, B.S., 2013. Raft forming system - An upcoming approach of gastroretentive drug delivery system. J. Control. Release 168, 151-165.

Qian, X., Ara, G., Mills, E., LaRochelle, W.J., Lichenstein, H.S., Jeffers, M., 2008. Activity of the histone deacetylase inhibitor belinostat (PXD101) in preclinical models of prostate cancer. Int. J. Cancer $122,1400-1410$.

Qiu, X., Yang, Y., Wang, L., Lu, S., Shao, Z., Chen, X., 2011. Synergistic interactions during thermosensitive chitosan- $\beta$-glycerophosphate hydrogel formation. RSC Adv. 1, 282.

Rice, J.J., Martino, M.M., De Laporte, L., Tortelli, F., Briquez, P.S., Hubbell, J.A., 2013. Engineering the Regenerative Microenvironment with Biomaterials. Adv. Healthc. Mater.

Rosenthal, R., Günzel, D., Finger, C., Krug, S.M., Richter, J.F., Schulzke, J.D., Fromm, M., Amasheh, S., 2012. The effect of chitosan on transcellular and paracellular mechanisms in the intestinal epithelial barrier. Biomaterials 33, 2791-2800.

Ruel-Gariépy, E., Leroux, J.-C., 2004. In situ-forming hydrogels--review of temperature-sensitive systems. Eur. J. Pharm. Biopharm. 58, 409-26.

Schinkel, J.K., Shao, S., Zahm, S.H., McGlynn, K.A., Shriver, C.D., Zhu, K., 2016. Overall and recurrence-free survival among black and white bladder cancer patients in an equal-access health system. Cancer Epidemiol. 42, 154-158.

Schuetz, Y.B., Gurny, R., Jordan, O., 2008. A novel thermoresponsive hydrogel based on chitosan. Eur. J. Pharm. Biopharm. 68, 19-25.

Senyigiti et al., 2015, 2015. Design and evaluation of an intravesical delivery system for superficial bladder cancer : preparation of gemcitabine $\mathrm{HCl}$-loaded chitosan - thioglycolic acid nanoparticles and comparison of chitosan / poloxamer gels as carriers. Int. J. Nanomedicine 10, 6493-6507.

Sharma, P., 2014. Cancer Immunology - Bladder Cancer [WWW Document]. Natl. Cancer Res. URL http://twww.cancerresearch.org/cancer-immunotherapy/impacting-all-cancers/bladder-cancer (accessed 11.2.15).

Shen, Z., Shen, T., Wientjes, M.G., O'Donnell, M. a., Au, J.L.S., 2008. Intravesical treatments of bladder cancer: Review. Pharm. Res. 25, 1500-1510.

Shen, Z.J., Wang, Y., Ding, G.Q., Pan, C.W., Zheng, R.M., 2007. Study on enhancement of fibronectinmediated bacillus Calmette-Guerin attachment to urinary bladder wall in rabbits. World J. Urol. $25,525-529$.

Shin, M.C., Zhang, J., Min, K.A., Lee, K., Byun, Y., David, A.E., He, H., Yang, V.C., 2014. Cell-penetrating peptides: Achievements and challenges in application for cancer treatment. J. Biomed. Mater. 
Res. - Part A. doi:10.1002/jbm.a.34859

Sievert, K.D., Amend, B., Nagele, U., Schilling, D., Bedke, J., Horstmann, M., Hennenlotter, J., Kruck, S., Stenzl, A., 2009. Economic aspects of bladder cancer: What are the benefits and costs? World J. Urol. 27, 295-300. doi:10.1007/s00345-009-0395-z

Simberg, D., Weisman, S., Talmon, Y., Barenholz, Y., 2004. DOTAP (and other cationic lipids): chemistry, biophysics, and transfection. Crit. Rev. Ther. Drug Carrier Syst. 21, 257-317.

Singh, B.N., Kim, K.H., 2000. Floating drug delivery systems: An approach to oral controlled drug delivery via gastric retention. J. Control. Release 63, 235-259.

Singh, N.K., Lee, D.S., 2014. In situ gelling pH- and temperature-sensitive biodegradable block copolymer hydrogels for drug delivery. J. Control. Release.

Smith et al., 2001, 2001. Urine detection of survivin and diagnosis of bladder cancer. JAMA 285, 324328.

Sogias, I.A., Williams, A.C., Khutoryanskiy, V. V., 2008. Why is chitosan mucoadhesive? Biomacromolecules 9, 1837-1842. doi:10.1021/bm800276d

Soler, R., Bruschini, H., Martins, J.R., Dreyfuss, J.L., Camara, N.O., Alves, M.T., Leite, K.R., Truzzi, J.C., Nader, H.B., Srougi, M., Ortiz, V., 2008. Urinary glycosaminoglycans as biomarker for urothelial injury: is it possible to discriminate damage from recovery? Urology 72, 937-42.

Štorha, A., Mun, E. a., Khutoryanskiy, V. V., 2013. Synthesis of thiolated and acrylated nanoparticles using thiol-ene click chemistry: towards novel mucoadhesive materials for drug delivery. RSC Adv. 3, 12275.

Supper, S., Anton, N., Seidel, N., Riemenschnitter, M., Schoch, C., Vandamme, T., 2013. Rheological study of chitosan/polyol-phosphate systems: Influence of the polyol part on the thermoinduced gelation mechanism. Langmuir 29, 10229-10237.

Swana et al., 1999. Tumor Content of the Antiapoptosis Molecule Survivin and Recurrence of Bladder Cancer. N. Engl. J. Med. 341, 452-453.

Tadros, T., 2013. Encyclopedia of Colloid and Interface Science, in: Tadros, T. (Ed.), . Springer Berlin Heidelberg, Berlin, Heidelberg, pp. 1046-1047.

Tamura, K., Kikuchi, E., Konno, T., Ishihara, K., Matsumoto, K., Miyajima, A., Oya, M., 2015. Therapeutic effect of intravesical administration of paclitaxel solubilized with poly(2methacryloyloxyethyl phosphorylcholine-co-n-butyl methacrylate) in an orthotopic bladder cancer model. BMC Cancer 15, 317. doi:10.1186/s12885-015-1338-2

Taylor, M.J., Tanna, S., Sahota, T., 2010. In vivo study of a polymeric glucose-sensitive insulin delivery system using a rat model. J. Pharm. Sci. 99, 4215-4227.

Team, T.A.C.S. medical and editorial content, 2016. Bladder Cancer Stages [WWW Document]. Am. Cancer Soc. URL https://www.cancer.org/cancer/bladder-cancer/detection-diagnosisstaging/staging.html (accessed 8.3.17).

TheraCoat Ltd., 2015. Pre-TURBT TC-3 Gel Intravesical Instillation in NMIBC (OPTIMA) [WWW Document]. URL

https://clinicaltrials.gov/ct2/show/NCT01803295?term=NCT01803295\&rank=1 (accessed 1.11.16).

Tomlinson, B., Lin, T., Dall'Era, M., Pan, C.-X., 2015. Nanotechnology in bladder cancer: current state of development and clinical practice. Nanomedicine 10, 1189-1201.

Tonglairoum, P., Brannigan, R.P., Opanasopit, P., Khutoryanskiy, V. V, 2016. Maleimide-bearing 
nanogels as novel mucoadhesive materials for drug delivery. J. Mater. Chem. B 4, 6581-6587. doi:10.1039/C6TB02124G

Torre, L.A., Bray, F., Siegel, R.L., Ferlay, J., Lortet-tieulent, J., Jemal, A., 2015. Global Cancer Statistics, 2012. CA a cancer J. Clin. 65, 87-108.

Tyagi, P., Tyagi, S., Kaufman, J., Huang, L., de Miguel, F., 2006. Local drug delivery to bladder using technology innovations. Urol. Clin. North Am. 33, 519-30, x.

Van der Lubben, I.M., Verhoef, J.C., Borchard, G., Junginger, H.E., 2001. Chitosan and its derivatives in mucosal drug and vaccine delivery. Eur. J. Pharm. Sci.

van Rhijn, B.W.G., Burger, M., Lotan, Y., Solsona, E., Stief, C.G., Sylvester, R.J., Witjes, J.A., Zlotta, A.R., 2009. Recurrence and progression of disease in non-muscle-invasive bladder cancer: from epidemiology to treatment strategy. Eur. Urol. 56, 430-42.

Wada, M., Jinno, H., Ueda, M., Ikeda, T., Kitajima, M., Konno, T., Watanabe, J., Ishihara, K., 2007. Efficacy of an MPC-BMA co-polymer as a nanotransporter for paclitaxel. Anticancer Res. 27, 1431-5.

Wang, W., Zhang, P., Shan, W., Gao, J., Liang, W., 2013. A novel chitosan-based thermosensitive hydrogel containing doxorubicin liposomes for topical cancer therapy. J. Biomater. Sci. Polym. Ed. 24, 1649-59.

Williams, S.K., Hoenig, D.M., Ghavamian, R., Soloway, M., 2010. Intravesical therapy for bladder cancer. Expert Opin. Pharmacother. 11, 947-958. doi:10.1517/14656561003657145

Wittmann, B.M., Stirdivant, S.M., Mitchell, M.W., Wulff, J.E., McDunn, J.E., Li, Z., Dennis-Barrie, A., Neri, B.P., Milburn, M. V., Lotan, Y., Wolfert, R.L., 2014. Bladder Cancer Biomarker Discovery Using Global Metabolomic Profiling of Urine. PLoS One 9, e115870.

Wright, C.S., Kellogg, G.E., 1996. Differences in hydropathic properties of ligand binding at four independent sites in wheat germ agglutinin-oligosaccharide crystal complexes. Protein Sci. 5, 1466-76. doi:10.1002/pro.5560050803

Wu, X.R., Lin, J.H., Walz, T., Häner, M., Yu, J., Aebi, U., Sun, T.T., 1994. Mammalian uroplakins: A a group of highly conserved urothelial differentiation-related membrane proteins. J. Biol. Chem. 269, 13716-13724.

Xu, J., Soliman, G.M., Barralet, J., Cerruti, M., 2012. Mollusk glue inspired mucoadhesives for biomedical applications. Langmuir 28, 14010-14017.

Yeung, C., Dinh, T., Lee, J., 2014. The Health Economics of Bladder Cancer: An Updated Review of the Published Literature. Pharmacoeconomics 32, 1093-1104.

Yi, S.M., Harson, R.E., Zabner, J., Welsh, M.J., 2001. Lectin binding and endocytosis at the apical surface of human airway epithelia. Gene Ther. 8, 1826-1832.

Yu, J., Lin, J.H., Wu, X.R., Sun, T.T., 1994. Uroplakins la and Ib, two major differentiation products of bladder epithelium, belong to a family of four transmembrane domain (4TM) proteins. J. Cell Biol. 125, 171-182.

Yu, L., Ding, J., 2008. Injectable hydrogels as unique biomedical materials. Chem. Soc. Rev. 37, 147381.

Zacchè, Martino Maria, Srikrishna, Sushma, Cardozo, L., 2015. Novel targeted bladder drug-delivery systems : a review. Res. Reports Urol. 7, 169-178.

Zhang, D., Sun, P., Li, P., Xue, A., Zhang, X., Zhang, H., Jin, X., 2013. A magnetic chitosan hydrogel for sustained and prolonged delivery of Bacillus Calmette-Guérin in the treatment of bladder 
cancer. Biomaterials 34, 10258-66.

Zhang, Q., Neoh, K.G., Xu, L., Lu, S., Kang, E.T., Mahendran, R., Chiong, E., 2014. Functionalized mesoporous silica nanoparticles with mucoadhesive and sustained drug release properties for potential bladder cancer therapy. Langmuir 30, 6151-61. 